\title{
Modulation of behavioral and hippocampal transcriptomic responses \\ in rat prolonged chronic unpredictable stress model by fluoxetine, eicosapentaenoic acid and lipopolysaccharide
}

Konstantin A. Demin* ${ }^{*+1,2,3}$, Tatiana O. Kolesnikova ${ }^{+1,3}$, David S. Galstyan ${ }^{+1,5}$, Nataliya A. Krotova ${ }^{1,2}$, Nikita P. Ilyin ${ }^{1,5}$, Ksenia A. Derzhavina ${ }^{1,2}$, Maria Seredinskaya ${ }^{1}$, Yuriy M. Kositsyn ${ }^{1}$, Dmitry V. Sorokin ${ }^{2}$, Maria O. Nerush ${ }^{2}$, Abubakar-Askhab S. Khaybaev², Sofia A. Pushkareva ${ }^{1}$, Tatyana Strekalova ${ }^{1}$, Alexey Masharsky ${ }^{4}$ and Allan V. Kalueff* ${ }^{5,6,7}$

${ }^{1}$ Institute of Translational Biomedicine, St. Petersburg State University, St. Petersburg, Russia ${ }^{2}$ Institute of Experimental Medicine, Almazov National Medical Research Centre, Ministry of Healthcare of Russian Federation, St. Petersburg, Russia

${ }^{3}$ Neuroscience Program, Sirius University of Science and Technology, Sochi, Russia

${ }^{4}$ Core Facility Centre for Molecular and Cell Technologies, St. Petersburg State University, SaintPetersburg, Russia

${ }^{5}$ Laboratory of Preclinical Bioscreening, Granov Russian Research Center of Radiology and Surgical Technologies, Ministry of Healthcare of Russian Federation, Pesochny, Russia ${ }^{6}$ School of Pharmacy, Southwest University, Chongqing, China

${ }^{7}$ Ural Federal University, Ekaterinburg, Russia

${ }^{+}$These authors contributed equally to the study

\section{*Co-corresponding authors:}

Allan V. Kalueff, Ph.D., School of Pharmacy, Southwest University, Chongqing, China. Tel/Fax: +1-240-899-9571 E-mail: avkalueff@gmail.com

Konstantin A. Demin, Institute of Translational Biomedicine SPBU, St. Petersburg State University, St. Petersburg, Russia. E-mail: deminkasci@gmail.com and k.demin@spbu.ru 


\begin{abstract}
Animal models are widely used to study common stress-induced affective disorders, such as anxiety and depression. Here, we examine behavioral and brain transcriptomic (RNA-seq) responses in rat prolonged chronic unpredictable stress (PCUS) model, and their modulation by 4-week treatment with fluoxetine, eicosapentaenoic acid (EPA), lipopolysaccharide (LPS) and their combinations. Overall, chronic stress produced anxiety-like phenotype, corrected by fluoxetine alone or in combination with EPA or LPS. EPA was anxiolytic in several tests, whereas LPS alone increased anxiety. PCUS evoked pronounced transcriptomic changes in rat hippocampi, differentially expressing $>200$ genes, while all pharmacological manipulations (except fluoxetine+EPA) affected only few genes. Gpr6, Drd2 and Adora2a were downregulated by chronic stress in a treatmentresistant manner, suggesting highly conserved nature of these pathogenetic genomic responses to chronic stress. Overall, these findings support the validity of rat PCUS paradigm as an effective tool to study stress-related pathologies, and calls for further research to probe how various conventional and novel drugs modulate behavioral and brain transcriptomic biomarkers of chronic stress in rodent models.
\end{abstract}

Keywords: chronic unpredictable stress; behavior; antidepressants; rats; transcriptome 


\section{Introduction}

Stress potently activates the sympatho-adrenomedullary, hypothalamic-pituitary-adrenal ${ }^{1,2}$, metabolic and immune systems ${ }^{3,4}$. Long-term stress evokes a wide range of pathological behavioral and physiological responses ${ }^{5,6}$, including neuroendocrine and neuroimmune deficits ${ }^{7-11}$ that often trigger affective disorders, such as anxiety and depression ${ }^{12-15}$. These neuropsychiatric disorders are widespread, debilitating, treatment-resistant ${ }^{16-18}$, poorly understood and complicated by multiple genetic and environmental determinants ${ }^{19,20}$. Various animal models, especially rodents and zebrafish (Danio rerio), are used to study the effects of stress on brain behavioral functions ${ }^{21-23}$. Commonly utilizing chronic unpredictable stress (CUS) protocols ${ }^{24-28}$, they typically expose rodents to varying stressors for several weeks ${ }^{26,28-31}$, evoking anxiety- and depression-like states ${ }^{32-34}$ with pathological neural alterations that resemble those observed clinically ${ }^{35}$.

However, clinically relevant chronic stress usually lasts longer than 5 weeks, and conventional antidepressants take several weeks to act, thus necessitating proper modelling of temporal dynamics $^{36,37}$. To address this problem, we have recently developed a novel prolonged chronic unpredictable stress (PCUS) model in zebrafish, based on $>10$-week stress and $>3$-week antidepressant treatment ${ }^{38}$. Capitalizing on this model further, here we translate it into rat chronic stress, using a 12-week PCUS protocol combined with 4-week treatment by a serotonergic antidepressant fluoxetine, a neuroprotective omega-3 polyunsaturated fatty acid (PUFA) eicosapentaenoic acid (EPA), and a pro-inflammatory bacteria-derived lipopolysaccharide (LPS) alone, or in combinations with fluoxetine.

\section{Methods}

\section{Animals}

A total of 140 Wistar rats (male: 1.5-2.5 months) were received from the Nursery for Laboratory Animals, Center for Preclinical and Translational Research (Almazov National Medical Research Centre, St. Petersburg, Russia). Prior to and during testing, rats were kept under standard conditions $\left(20-22^{\circ} \mathrm{C}, 55 \%\right.$ humidity, food and water ad libitum, $12: 12 \mathrm{~h}$ light/dark cycle; lights on 08:00). All rats were from the same population and were randomly allocated into experimental groups using a random 
number generator (https://www.random.org/). All experimental animal manipulations were approved by the Ethics committee of the Institute of Experimental Medicine at Almazov National Medical Research Center (approval number 20-14П3\#V2). All animals tested were included in final analyses, without removing the outliers. All experiments were performed as planned, and all analyses and endpoints assessed were included without omission.

Rodents are widely used as a tool for CNS pathology modeling, including stress-related pathological states, due to the high homology of the core stress mechanisms with humans. The Wistar strain was chosen here as the best-studied and widely used strain in rat biomedical modeling and preclinical studies ${ }^{39}$, and because studies with this strain are highly reproducible in neurogenetics and CNS disorders modeling, benefit from genetic stability of this strain ${ }^{39}$, and represent a more populationally valid and translationally relevant approach for the purposes of this study. Only male rats were used in the present study, chosen based on overt sex differences in rat chronic stress assays ${ }^{40-}$ 42 and the high impact of the estrous cycle on female rat behavior ${ }^{43}$ which may negatively affect the results.

\section{Prolonged Chronic Unpredictable Stress (PCUS)}

Experimental rats were exposed for 12 weeks to various stressors daily, similar to 44,45 , including crowding, smell, novel objects, flashing light, water/food deprivation, shaking, swimming, novelty, day/night inversion, predator exposure, darkness and light for $24 \mathrm{~h}$, intermittent and stroboscopic lighting, cage tilt, noise (drill sound), social isolation, and sleep deprivation (Table 1). The duration of stress exposure was chosen here based on previous rodents CUS protocols ${ }^{45}$.

Control rats were housed similarly to the experimental cohort but remained experimentally naïve for the entire duration of the study. On Day 57, the stressed rodent cohort was divided into six groups (chronic stress alone or with chronic fluoxetine, eicosapentaenoic acid (EPA), lipopolysaccharide (LPS), fluoxetine+EPA, and fluoxetine+LPS) for the final 4 weeks of the study.

Since LPS was injected intraperitoneally once a week, control animals were also similarly injected intraperitoneally with sodium chloride solution. Fluoxetine (Biocom Ltd., Stavropol, Russia) is a commonly used antidepressant ${ }^{46-48}$ widely tested in various animal models, including rodents ${ }^{49-}$ 
${ }^{52}$. Rats were administered $0.5 \mathrm{~mL}$ distilled water containing $5 \mathrm{mg} / \mathrm{kg}$ fluoxetine using oral syringes. The duration of treatment, its dose and route of administration were selected based on the previous studies in stress-related models ${ }^{38,53}$.

LPS from Escherichia coli O55:B5 (Sigma Aldrich, St. Louis, MO, USA), was chosen here for its ability to induce inflammation ${ }^{54}$ following 0.5 -ml weekly injections containing $0.1 \mathrm{mg} / \mathrm{kg}$ LPS. The dose was chosen based on rodent LPS studies ${ }^{55-59}$, and adjusted for chronic exposure. EPA was used here for its anti-inflammatory properties ${ }^{60}$, was obtained from Tokyo Chemical Industry Co. Ltd. (Tokyo, Japan) and orally administered by oral syringes in $0.5 \mathrm{~mL}$ sunflower oil containing 275 $\mathrm{mg} / \mathrm{kg}$ of EPA, based on earlier rodent studies ${ }^{61-64}$. Animals from all groups were tested on two separate days, due to the limited lab testing capacity per day. On each day, all animals were assessed in behavioral tests in the same way, in similar conditions and by the same highly-trained observers, and were euthanized using the same approved procedures.

\section{Behavioral testing}

Following an 11-week PCUS protocol, behavioral phenotypes were assessed in a battery consisting of the open field (OF) test, elevated plus-maze test (EPMT) and grooming test (GT). Behavioral assays were performed in the order of increasing stress intensity, aiming to reduce the effect of the preceding testing. Prior to testing, the rats were kept for $2 \mathrm{~h}$ in a testing room for acclimation and were returned to the holding room after testing. Behavioral testing was performed between 10.00 and $17.00 \mathrm{~h}$ and was recorded with a SJ4000 action camera (SJCAM, Ltd., Shenzhen, China) at 60 frames/s. Experimenters were blinded to the treatments during behavioral testing, including statistical and video analyses, and used individual codes for rats/groups identification. Manual analysis of behavioral data was performed by two highly-trained observers (blinded to the groups) with inter- and intra-rater reliability of $>0.85$, as assessed by Spearman correlation as part of the laboratory's standard operating procedure (SOP).

The OF apparatus was a gray-colored plastic square box $(97$ length $\times 97$ width $\times 40$ height, cm $)$ (OpenScience, Krasnogorsk, Russia), mounted on a mobile cart at $55 \mathrm{~cm}$ height. The illumination of the arena was $90 \mathrm{Lx}$. The animals were placed in the center of the open field facing in the opposite 
direction to the researcher. Arena was cleaned by sponge with $70 \%$ ethanol after each animal and dried with a rag to remove olfactory cues. Each rat was recorded separately, immediately after being taken from the home cage, by a SJ4000 action camera, fixed at the top. $5 \mathrm{~min}$ of behavior were recorded, assessing horizontal (total distance traveled $(\mathrm{cm})$ ) and vertical exploratory activity (total number and duration (s) of supported (paws on the wall) and unsupported (paws in the air) vertical rearing behavior), duration and latency of freezing $(\mathrm{s})^{65,66}$, using Noldus EthoVision XT11.5 (Noldus IT, Wageningen, Netherlands) for automated scoring and RealTimer software (OpenScience) for manual scoring.

The EPMT apparatus ${ }^{67}$ consisted of 4 cross-connected gray-colored plastic arms (50 length $\times 14$ width, cm) $($ OpenScience $)$ placed on 55-cm tall cart. The two 'open' arms had 1-cm edges, and the two 'closed' arms had $30 \mathrm{~cm}$-tall walls. The apparatus was illuminated using $65 \mathrm{wt}$ bulbs, directed to open arms (400 Lx), whereas the testing room and closed arms were dimly lit (30 Lx). During the testing, animals were placed in the central area of the apparatus facing from the researcher for $5 \mathrm{~min}$ and their behavior were recorded and analyzed using RealTimer software, scoring vertical motor activity (total number and duration (s) of supported and unsupported rearing behavior), the number and duration (s) of freezing bouts, as well as the latency (s) and total time spent (s) in open and closed arms ${ }^{67}$.

GT was used to characterize in-depth rat self-grooming behavior and its complex behavioral patterns, according to ${ }^{68-70}$. For this, rats were individually placed in the transparent glass cylindrical jar $(20 \mathrm{~cm} \text { in diameter, } 45 \mathrm{~cm} \text { high })^{69}$ and their grooming behavior were recorded using a SJ4000 action camera for $10 \mathrm{~min}$, assessing the duration of total, rostral (paw, face and head) and caudal (body, tail and genital) grooming bouts $(s)^{69,71-73}$. We have further visually analyzed grooming microstructure (Supplementary Fig. S4) using ethograms and compared the duration (s) for each type of grooming behavior individually as well as the percent of incorrect grooming transitions for animals with total grooming time $>10 \mathrm{~s}^{69,71-73}$. An incorrect transition was defined as any transition between grooming stages that violated normal cephalo-caudal progression (paws- $>$ face- $>$ head- $>$ body$>$ tails/genitals). Between the animals, the jar was cleaned with $70 \%$ ethanol. 


\section{RNA-sequencing}

Brain samples for transcriptomic analyses were collected without pooling ( 1 brain per sample) one day after the last behavioral test, between 9:00 and 19.00. The 1-day interval was used here to minimize concomitant immediate genomic effects of behavioral testing and/or handling ${ }^{74}$. Rats $(\mathrm{n}=3)$ for RNA-sequencing analysis were chosen from the groups using a random number generator (https://www.random.org/). Rats were quickly euthanized in small animal inhalation anesthesia chamber (SomnoSuite, Kent Scientific, Connecticut, USA) using $5 \%$ isoflurane, and their brains dissected on ice and stored in liquid nitrogen for analyses. RNA isolation was performed using TRIreagent (MRC, Catalog number 118), according to manufacturer instructions. RNA quality was verified with Quantus, electrophoresis, and QIAxel. PolyA RNA was purified with Dynabeads mRNA Purification Kit (Ambion) ${ }^{74}$. Illumina library was made from polyA RNA with NEBNext Ultra II Directional RNA Library Prep Kit for Illumina (NEB) according to manual ${ }^{74}$. Sequencing was performed on Illumina HiSeq4000 with 151 bp read length, with at least 20 million reads generated for each sample.

\section{Statistical analyses and data handling}

The study used Generalized Linear Models (GZLM) to analyze behavioral data, similar to ${ }^{74}$. GZLM is a widely used method of statistical analyses ${ }^{75-77}$ that allows variables to have distributions other than normal, thus making it suitable both for nonparametric and parametric data ${ }^{75,76,78-80}$. We performed the Wald chi-square $\left(\chi^{2}\right)$ analysis of variance (ANOVA, Type II) for GZLM fits, followed by Tukey's post-hoc testing for significant GZLM/Wald pair-wise comparison data. To count for potential effects of testing day we used test-day, group and their interaction effects to construct GZLM model. However, we further analyzed and discuss only the group effects as the only one relevant to the study aims. To choose optimal GZLM distribution and link functions (goodness of fit) for each endpoint, we compared, where applicable, the Akaike information criterion (AIC) levels ${ }^{81,82}$ of Gaussian distribution (identity link), Poisson distribution (with log or squared root links), Gamma distribution (inverse and log links) and Inverse Gaussian distribution (with inverse and log links), choosing the least AIC score (indicating the model most likely to be correct) ${ }^{83}$, similar to ${ }^{74}$. GZLM 
analyses were performed using the R software ${ }^{84}$.

Unless specified otherwise, all data were expressed as mean \pm standard error of mean (S.E.M.), and $\mathrm{P}$ set as $<0.05$ in all behavioral analyses. Analyses of all data were performed offline without blinding the analysts to the treatments, since all animals and samples were included in analyses, data were analyzed in a fully unbiased automated method, and the analysts had no ability to influence the results of the experiments, as in ${ }^{85}$. The study experimental design and its description here, as well as data analysis and presenting, adhered to the ARRIVE guidelines for reporting animal research and the PREPARE guidelines for planning animal research and testing.

\section{Differential Gene Expression (DE) and Gene Set Enrichment Analysis (GSEA)}

To analyze differential gene expression, reads were mapped to the rat Rnor_6.0 reference genome using STAR spliced aligner ${ }^{86}$ and further processed using featureCounts ${ }^{87}$ to obtain raw gene counts (usegalaxy.org). A total of 32883 genes were used for analyses using the R software ${ }^{84}$ with the Bioconductor ${ }^{88}$ and DESeq $2^{89}$ packages. This method was chosen as an efficient tool to study experiments with 12 or fewer replicates per condition, that is stable even within 0.5 fold-change thresholds, and generally consistent with other tools ${ }^{90}$. First, all rows without counts or only with a single count across all samples were removed from analyses, yielding 23684 genes. Principal Components Analysis (PCA) of the regularized log (rlog)-transformed ${ }^{89}$ data counts were used as a preprocessing tool to tackle any outlier samples using pcaExplorer R package ${ }^{91}$. For PCA analyses, 500 most varied genes were used, and the outliers were determined graphically, using the PC1-PC2 plot, identifying LF3 (LPS-Fluoxetine sample number 3) and K1 (Control sample number 1) as outliers that were excluded from further analysis (Supplementary Fig. S1). PCA analyses of the remaining samples revealed more closely-ordered samples with no obvious outliers (Supplementary Fig. S2), but elliptic grouping of the samples with 0.95 CI did not reveal any clear clusters. PC1 and PC2 together determined more than a half (58.7\%) of the sample variance, whereas PC3-8 each determined less than 15\% (Supplementary Fig. S3). Finally, we identified top 10 down- and upregulated genes loadings for PC1 and PC2 (genes with largest impact on PC).

Differential expression (DE) analyses on the Negative Binomial (Gamma-Poisson) 
distribution were next performed by estimating size factors, dispersion, and negative binomial generalized linear models and Wald statistics using the DESeq function ${ }^{74,92}$. The p-values were adjusted using the Benjamini-Hochberg correction. We further adjusted p-value and false discovery rate (FDR) for multiple comparison using the Bonferroni correction, thus finally setting FDR 0.01(6) for pair-wise comparisons vs. control group and 0.02 for pair-wise comparisons vs. chronically stressed PCUS group. We next compared resultant DE genes between groups identifying uniquely represented as well as co-represented genes. Venn diagrams were constructed using the VennDiagram R package ${ }^{93}$.

Gene Set Enrichment Analysis (GSEA) is a widely-spread method to assess gene expression data arranged in molecular sets from curated databases, allowing for a better detection of molecularly relevant changes ${ }^{94-97}$. However, original GSEA approaches have some limitations, including the inability to handle datasets of different sizes and complex experimental designs ${ }^{98}$. Relatively novel type of GSEA, the Generally Applicable Gene Set Enrichment (GAGE) for the pathways analysis addressed these limitations ${ }^{98}$, enabling to choose independent pathways databases to be analyzed depending on research goals and consistently outperforming classical GSEA methods ${ }^{98}$. The KEGG enrichment analyses were performed on normalized and log2-transformed counts using the GAGE package $^{98}$ and two-sample Student's t-test for unpaired group comparison of differential expression of gene sets. The FDR cut-off was set at 0.01(6) for pair-wise comparisons vs. control group and 0.02 for pair-wise comparisons vs. chronically stressed group, similarly to DE analysis. The resultant sets were compared between groups, similarly to DE analysis, and visualized by Venn diagrams.

\section{Results}

In the open field (OF) test, PCUS produced several significant treatment effects (Table 3, Fig.1 and Supplementary Tables S1-S2), as stressed rats reduced frequency and duration of exploratory vertical rearing behavior. Fluoxetine+EPA and fluoxetine+LPS exposure in this test increased the duration and frequency of rearing vs. stress, whereas PCUS, EPA, fluoxetine+EPA and fluoxetine+LPS elevated the duration of anxiety-like freezing behavior vs. control rats $(\mathrm{p}<0.05$, Tukey test, Table 3, Fig.1 and Supplementary Tables S1-S2). The LPS group decreased freezing 
frequency only vs. stressed rats, fluoxetine+LPS elevated freezing frequency vs. control $(\mathrm{p}<0.05$, Tukey test), whereas horizontal locomotor activity, as well as frequency and duration of supported rearing behavior, were unaltered vs. control and stressed animals ( $p>0.05$, Tukey test, Table 3, Fig. 1 and Supplementary Tables S1-S2).

In the elevated plus-maze test (EPMT), stressed rats spent less time in the aversive open arms vs. control $(\mathrm{p}<0.05)$, and fluoxetine, EPA, fluoxetine+EPA and fluoxetine+LPS rats increased this behavior vs. stress group ( $\mathrm{p}<0.05$, Tukey test, Table 3, Fig. 2 and Supplementary Tables S1-S2). With unaltered open arm entries in all groups, stressed rats made fewer closed entries vs. control, and EPA, LPS, fluoxetine+EPA exposure also increased this endpoint vs. stress $(\mathrm{p}<0.05$, Tukey test, Table 3, Fig. 2 and Supplementary Tables S1-S2). In addition, fluoxetine+LPS increased the number of closed arm entries vs. control and stress, with unaltered freezing behavior in all experimental groups (Table 3, Fig. 2 and Supplementary Tables S1-S2).

In the grooming test (GT), PCUS induced overt behavioral effects (Fig. 3, Supplementary Fig. S4 and Supplementary Tables S1-S2), with caudal grooming increased vs. control in all groups, except LPS ( $p<0.05$, Tukey test), and reduced by EPA and LPS vs. stress, suggesting potential antistress beneficial effects of these treatments $(\mathrm{p}<0.05$, Tukey test, Table 3, Fig.3, Supplementary Fig. S4 and Tables S1-S2). Furthermore, GT analyses revealed increased body, tail and head self-grooming in all groups (except fluoxetine+LPS) vs. controls ( $\mathrm{p}<0.05$, Tukey test, Table 3, Supplementary Fig. S4, Supplementary Tables S1-S2). Both EPA and LPS groups reduced head and body, but not tail grooming, compared to stress group ( $\mathrm{p}<0.05$, Tukey test), with no other differences in this test ( $>0.05$, ANOVA on GZLM, Table 3, Fig. 3, Supplementary Fig. S4 and Tables S1-S2).

\section{Differential gene expression and gene set expression analysis}

Although PCA analysis did not identify any clusters and showed high heterogeneity among brain samples (Supplementary Fig. S2), it revealed top 10 up- and down-regulating PC1 and PC2 factors (Fig. 6). Our transcriptomic analyses yielded 361 differentially expressed (DE) genes in stress, 12 in fluoxetine, 4 in LPS, 348 in EPA, $1(C g a)$ in fluoxetine+LPS and 452 in fluoxetine+EPA $(\mathrm{q}<0.01(6)$ vs. control group, Fig. 5 and Supplementary Table S3). Three DE genes (Gpr6, Drd2, 
Adora $2 a$ ) were downregulated in all analyses vs. control group (except fluoxetine+LPS vs. control), supporting their likely core role in stress and its resistance to fluoxetine or EPA treatment. We also identified 81 DE genes in fluoxetine group, 8 in EPA, 40 in LPS, 4 in fluoxetine+LPS and 299 in fluoxetine+EPA vs. stress group $(\mathrm{q}<0.02$, Fig. 5 and Supplementary Table S3).

The Gene Set Enrichment Analysis (GSEA) identified 27 enriched sets in stress, 5 in fluoxetine, 2 in LPS and 26 in fluoxetine+EPA groups, with only rno03040 Spliceosome downregulated in both EPA and fluoxetine+LPS groups ( $q<0.01(6)$ vs. control). We also found 25 enriched sets in fluoxetine, 2 in LPS, 5 in EPA, 20 in fluoxetine+LPS and 58 sets in fluoxetine+EPA vs. stressed group $(\mathrm{q}<0.02$, Fig. 6 and Supplementary Table S4).

\section{Discussion}

The present study, for the first time, applied clinically relevant PCUS model in rats (based on our recently developed zebrafish PCUS model ${ }^{38}$ ) and characterized a wide range of behavioral and transcriptomic responses in stressed and drug-treated rats. The 12-week PCUS protocol aimed to recapitulate in rats pronounced and stable behavioral and molecular clinical phenotypes induced by chronic stress, and consistent with overt alterations in zebrafish behavior and neurochemistry ${ }^{38}$, hence strongly supporting further cross-species translation between stress models. The present study also explored potential pharmacological and dietary therapies in the PCUS model, including both widely used conventional antidepressant (fluoxetine) and putative novel (EPA) anti-stress treatments, as well as the combination of PCUS with a pro-inflammatory agent LPS that may exacerbate PCUS effects.

In general, our behavioral analyses reveal overt anxiety induced in rats by PCUS (manifested in reduced vertical exploration and elevated freezing in $\mathrm{OF}$, and increased closed arm behavior in EPMT), as well as its recovery by fluoxetine and its combinations (Fig. 1). Similarly, in EPMT, fluoxetine alone or with EPA or LPS, increased open arm duration, suggesting an antistress effect. Collectively, these findings parallel other rodent chronic stress models ${ }^{99,100}$ and phenotypes observed in clinical patients ${ }^{101}$, hence further supporting translational validity of the present PCUS model. Likewise, PCUS increased head, body and tail grooming, suggesting increased anxiety in stressed rats $^{69,102}$. Interestingly, only EPA and LPS significantly reduced caudal and head grooming vs. stress 
group (Fig. 3 and Supplementary Fig. S4), suggesting that while classical anxiety indices (e.g., rearing and freezing) and anxiety-related grooming phenotypes may correlate, they can be differentially affected by some treatments, likely reflecting distinct (i.e., exploratory vs. displacement activity) behavioral domains.

Importantly, chronic fluoxetine reversed most of PCUS behavioral effects, even when stress was exacerbated by LPS. Generally in line with anxiolytic ${ }^{103}$, antidepressant ${ }^{104}$ and antiinflammatory ${ }^{105}$ effects observed for SSRIs clinically, this reinforces the overall translational validity of the PCUS model developed here. This profile also parallels fluoxetine effects in other rodent stress studies, including the modulation of anxiety in various shorter CUS protocols ${ }^{51,106-108}$. Interestingly, fluoxetine+LPS unexpectedly produced robust anxiolytic effect on rat OF rearing (vs. stressed group) and open arm exploration in EPMT, but increased freezing duration in both tests, resembling hypolocomotor profile reported for this combination in zebrafish PCUS model ${ }^{38}$.

EPA did not rescue anxiety-like OF behavior, but was effective in both EPMT and GT. Fluoxetine+EPA was more effective in OF, rescuing stress-evoked rearing (but not freezing) behavior and EPMT anxiety, similar to EPA treatment. These results are in line with some clinical studies on positive effects of EPA in depression ${ }^{109,110}$, and the fact that fluoxetine+EPA is more efficient than either monotherapy ${ }^{111}$. This is also consistent with our earlier zebrafish PCUS data on lesser efficiency of EPA alone (than in combination with fluoxetine $)^{38}$. Thus, further studies are needed to better understand potentially synergistic, shared across taxa effects of fluoxetine and EPA in the PCUS model presented here.

As a key component of gram-negative bacterial membrane, LPS triggers inflammation via immune and non-immune mechanisms ${ }^{112}$, promoting the release of pro-inflammatory cytokines interleukin (IL) IL-1 $\beta$ and tumor necrosis factor- $\beta$ (TNF- $\beta)^{113}$. Proinflammatory cytokines are often associated with various mental illnesses, especially depression ${ }^{114}$. Thus, suggesting that LPS+stress combination may exert anxiety phenotype and can be used for studying stress-neuroimmune interplay. EPA is a critical PUFA with multiple physiological functions in vivo, including antiinflammatory properties beneficial in various psychiatric disorders ${ }^{115,116}$. Thus, the fluoxetine+EPA 
combination can be promising for treating stress-related pathogenesis.

Importantly, there were also some limitations of the present study. For example, our transcriptomic analyses utilized only one brain region (hippocampus) in contrast to tissue-specific or multi-region transcriptomic studies, and thus may mask some cell differences and/or complicate probing other regions involved in stress pathology. Furthermore, rodents, like other model organisms, display intra-species variation ${ }^{117-119}$, including behavioral sex differences ${ }^{41,120-122}$, that may play a role in stress mechanisms and effects on pharmacologically evoked phenotypes as well. Although assessing intraspecies variability was outside the scope of the present study, it merits further scrutiny in subsequent follow-up studies.

In addition to behavioral deficits, exposure to PCUS caused pronounced transcriptomic changes in 361 genes, that were further corrected with fluoxetine treatment. For instance, altered expression of G-protein receptor (GPCR)-related genes may be relevant given their wide use as molecular targets for pharmacological interventions ${ }^{123}$. PCUS rats over-expressed Gpr84 (that controls the levels of inflammatory mediators) ${ }^{124,125}$, but downregulated Gpr176 (whose protein inhibits cAMP signaling) ${ }^{126}$ and Gpr6 (associated with sphingosine-1-phosphate signaling ${ }^{127}$, learning $^{128}$ and neurite outgrowth ${ }^{129}$, also linked to Parkinson's disease and schizophrenia ${ }^{130}$ ). Animal $^{131,132}$ and human studies ${ }^{133,134}$ have implicated the dopamine D2 receptor gene (Drd2) in anxiety and depression, and Adora2a (Adenosine A2A receptor) gene in the regulation of glutamate and dopamine release, suggesting $\operatorname{Drd} 2$ as a potential therapeutic target for the treatment of insomnia, pain, depression and Parkinson's disease ${ }^{135,136}$.

PCUS (vs. control) rats also showed upregulated immunoglobulin superfamily member 2 (Igsf2) and NCK Associated Protein 1 Like (Nckap1l), directly or indirectly modulating CNS functions ${ }^{137,138}$, as well as the expression of Kinesin-like protein 17 (Kif17) gene, involved in microtubule transport of the N-methyl-D-aspartate (NMDA) receptor subunit $\mathrm{Nr} 2 \mathrm{~b}$ (Grin2b) in hippocampal neurons ${ }^{139,140}$, collectively indicating overt brain transcriptomic responses to PCUS.

Fluoxetine corrected most behavioral and transcriptome alterations induced by PCUS in rats, and decreased the expression of the Chemerin Chemokine-Like Receptor 1 (Cmklrl) gene involved 
in inflammation and depression ${ }^{141}$, hence supporting not only antidepressant, but also antiinflammatory effects of SSRIs in affective pathogenesis. Interestingly, we identified several genes (Gpr6, Drd2 and Adora2a) whose expression was reduced in all groups (except for fluoxetine+LPS) compared to controls. This shared expression pattern may support the core role of these genes in the stress, as they remained treatment-resistant here, and may therefore underlie treatment-resistant clinical affective pathologies.

While EPA, unlike fluoxetine, did not correct behavioral deficits here, they both upregulated the expression of Solute Carrier Family 9 Member B1 (Slc9b1) gene important for DNA methylation $^{142}$ and various stress-related brain disorders ${ }^{143-145}$. In line with this, EPA and fluoxetine both treat clinical depression, whereas their combination is more efficient than either of them alone $^{146,147}$. Fluoxetine+EPA rats upregulated brain Superoxide Dismutase 3 (Sod3) gene, involved in anti-inflammation and neuroprotection in stress ${ }^{148}$. In addition, both fluoxetine and its combination with EPA reduced the expression of Cut Like Homeobox 2 (Cux2; vs. stress) that regulates the development of dendrites, dendritic spines and synapses of neocortical neurons in mice, and has been linked to clinical affective disorders and schizophrenia ${ }^{149,150}$.

LPS, unlike EPA, initiates an inflammatory response via both immune and non-immune factors $^{112}$. In contrast to PCUS, LPS downregulated the expression of Toll-like receptor 7 (Tlr7) that regulates neurodevelopment and brain functions, and whose deletion in mice lowers anxiety behavior $^{151}$. In addition, LPS downregulates rat Calcium/Calmodulin Dependent Protein Kinase II Beta (Camk2b; vs. chronic stress), a gene upregulated in patients with schizophrenia and depression $^{152}$. Overall, these changes suggest that LPS treatment may somewhat worsen physiological impact of chronic stress.

Comparing our present rat PCUS results with mouse data in a different, social defeat-based chronic stress model, ${ }^{153}$, we note that both stressors reduce hippocampal expression of Dedicator Of Cytokinesis 10 (Dock10), a poorly studied immune gene ${ }^{154}$. Cardiac muscle troponin T (Tnnt2) orthologues (Tnnt2 and tnnt2a), parts of the troponin complex, were both upregulated in PCUS rats and in zebrafish subjected to 5-week PCUS ${ }^{74}$. However, novel data mining tools are needed to target 
species-specific and cross-species data, also aiming to identify evolutionarily conserved core aspects that may be used to better compare and interpret animal data.

In summary, our rat PCUS protocol induced anxiety-like behavioral effects rescued by fluoxetine, but only partially by EPA. Fluoxetine also recovered most of PCUS-evoked behavioral and molecular alterations alone, or in combination with EPA or LPS. Finally, PCUS robustly affected rat brain transcriptomic profiles, downregulating Gpr6, Drd2 and Adora2a genes in most treatment groups (except fluoxetine+LPS), supporting the highly conserved role of these genes in chronic stress pathogenesis.

\section{Acknowledgements}

The research was supported by the Russian Science Foundation (RSF) Grant 19-15-00053. AVK is the Chair of the International Zebrafish Neuroscience Research Consortium (ZNRC) and President of the International Stress and Behavior Society (ISBS, www.stress-and-behavior.com) that coordinated this collaborative multi-laboratory project. The consortium provided a collaborative idea exchange platform for this study. It is not considered as an affiliation, and did not fund the study. This study utilized equipment of the Core Facilities Centre "Centre for Molecular and Cell Technologies" of St. Petersburg State University. The funders had no role in the design, analyses, and interpretation of the submitted study, or decision to publish.

\section{Data availability}

The datasets generated and/or analyzed during the current study are available from the corresponding authors upon reasonable request. 
bioRxiv preprint doi: https://doi.org/10.1101/2021.12.05.471274; this version posted December $7,2021$. The copyright holder for this preprint (which was not certified by peer review) is the author/funder, who has granted bioRxiv a license to display the preprint in perpetuity. It is made available under aCC-BY-NC-ND 4.0 International license.

Table 1. Summary of the rat PCUS protocol used in the present study (see Table 2 for details of specific stressors)

\begin{tabular}{|c|c|}
\hline Day & Stress procedures \\
\hline 1 & Strong smell + noise $30 \mathrm{~min}+$ bright light $(150 \mathrm{Lx}) 24 \mathrm{~h}$ \\
\hline 2 & Flashing light $4 \mathrm{~h}+$ crowding $6 \mathrm{~h}+$ water deprivation $12 \mathrm{~h}$ \\
\hline 3 & Social isolation $6 \mathrm{~h}+$ cage tilt $24 \mathrm{~h}$ \\
\hline 4 & Intermittent lighting + swimming $20 \mathrm{~min}+$ food deprivation \\
\hline 5 & Shaking $20 \mathrm{~min}+$ noise $4 \mathrm{~h}+$ day/night inversion \\
\hline 6 & Novelty stress + predator exposure $24 \mathrm{~h}+$ darkness $24 \mathrm{~h}$ \\
\hline 7 & Stroboscopic lighting (150 Lx) $6 \mathrm{~h}+$ novel objects + strong smell \\
\hline 8 & Intermittent lighting + cage tilt $24 \mathrm{~h}+$ day/night inversion \\
\hline 9 & Crowding $8 \mathrm{~h}+$ shaking $30 \mathrm{~min}$ \\
\hline 10 & Food and water deprivation (with empty bottles) $12 \mathrm{~h}+$ light $24 \mathrm{~h}$ \\
\hline 11 & Flashing light $8 \mathrm{~h}+$ noise $2 \mathrm{~h}+$ sleep deprivation \\
\hline 12 & Swimming $30 \mathrm{~min}+$ shaking $10 \mathrm{~min}+$ predator exposure $24 \mathrm{~h}$ \\
\hline 13 & Novel objects $24 \mathrm{~h}+$ day/night inversion \\
\hline 14 & Strong smell + noise $4 \mathrm{~h}+$ intermittent lighting \\
\hline 15 & Social isolation $10 \mathrm{~h}+$ cage tilt $24 \mathrm{~h}$ \\
\hline 16 & Novelty stress + predator $24 \mathrm{~h}+$ light $24 \mathrm{~h}$ \\
\hline 17 & Noise $6 \mathrm{~h}+$ flashing light $4 \mathrm{~h}+$ food deprivation $24 \mathrm{~h}$ \\
\hline 18 & Swimming $30 \mathrm{~min}+$ water deprivation $12 \mathrm{~h}+$ day/night inversion \\
\hline 19 & Crowding $8 \mathrm{~h}+$ strong smell + light $24 \mathrm{~h}$ \\
\hline 20 & Flashing light $10 \mathrm{~h}+$ cage tilt $24 \mathrm{~h}+$ predator $24 \mathrm{~h}$ \\
\hline 21 & Stroboscopic lighting $8 \mathrm{~h}+$ novel objects $24 \mathrm{~h}$ \\
\hline 22 & Strong smell + intermittent lighting + sleep deprivation $24 \mathrm{~h}$ \\
\hline 23 & Noise $8 \mathrm{~h}+$ food/water deprivation + darkness $24 \mathrm{~h}$ \\
\hline 24 & Flashing light $8 \mathrm{~h}+$ novel objects and cage tilt $24 \mathrm{~h}$ \\
\hline 25 & Swimming $30 \mathrm{~min}+$ stroboscopic lighting $6 \mathrm{~h}+$ predator exposure $24 \mathrm{~h}$ \\
\hline 26 & Crowding $6 \mathrm{~h}+$ food deprivation $10 \mathrm{~h}+$ darkness $24 \mathrm{~h}$ \\
\hline 27 & Shaking $40 \mathrm{~min}+$ flashing light $8 \mathrm{~h}$ \\
\hline 28 & Social isolation $8 \mathrm{~h}$ with noise $6 \mathrm{~h}+$ day/night inversion \\
\hline 29 & Novelty stress + stroboscopic lighting with novel objects $8 \mathrm{~h}+$ predator exposure $24 \mathrm{~h}$ \\
\hline 30 & Crowding $8 \mathrm{~h}+$ water deprivation (with empty bottle) $12 \mathrm{~h}+$ cage tilt $24 \mathrm{~h}$ \\
\hline 31 & Shaking 35 min + darkness 24 h with flashing light $(4 \mathrm{~h})$ \\
\hline 32 & Noise $6 \mathrm{~h}+$ intermittent lighting + sleep deprivation \\
\hline 33 & Social isolation $8 \mathrm{~h}+$ light $24 \mathrm{~h}+$ food deprivation $24 \mathrm{~h}$ \\
\hline 34 & Swimming $25 \mathrm{~min}+$ intermittent lighting + cage tilt $24 \mathrm{~h}$ \\
\hline 35 & Flashing light $10 \mathrm{~h}+$ novel objects $24 \mathrm{~h}+$ noise $2 \mathrm{~h}$ \\
\hline 36 & Shaking $30 \mathrm{~min}+$ predator $24 \mathrm{~h}+$ light $24 \mathrm{~h}$ \\
\hline 37 & Noise $4 \mathrm{~h}+$ food deprivation + day/night inversion \\
\hline 38 & Crowding $6 \mathrm{~h}+$ intermittent lighting \\
\hline 39 & Shaking $40 \mathrm{~min}+$ novel objects + stroboscopic lighting $6 \mathrm{~h}$ \\
\hline 40 & Swimming $20 \mathrm{~min}+$ predator $24 \mathrm{~h}+$ water deprivation $24 \mathrm{~h}$ \\
\hline 41 & Social isolation $10 \mathrm{~h}+$ darkness $24 \mathrm{~h}+$ food deprivation $24 \mathrm{~h}$ \\
\hline
\end{tabular}


bioRxiv preprint doi: https://doi.org/10.1101/2021.12.05.471274; this version posted December 7, 2021. The copyright holder for this preprint (which was not certified by peer review) is the author/funder, who has granted bioRxiv a license to display the preprint in perpetuity. It is made available under aCC-BY-NC-ND 4.0 International license.

\begin{tabular}{|c|c|}
\hline 42 & Noise $6 \mathrm{~h}+$ flashing light $8 \mathrm{~h}+$ cage tilt $24 \mathrm{~h}$ \\
\hline 43 & Novel objects $24 \mathrm{~h}+$ strong smell + light $24 \mathrm{~h}$ \\
\hline 44 & Swimming $5 \mathrm{~min}+$ stroboscopic lighting $8 \mathrm{~h}+$ predator $24 \mathrm{~h}$ \\
\hline 45 & Crowding $10 \mathrm{~h}+$ noise $12 \mathrm{~h}+$ food deprivation $24 \mathrm{~h}$ \\
\hline 46 & Novelty stress + shaking $20 \mathrm{~min}+$ darkness $24 \mathrm{~h}$ \\
\hline 47 & Noise $4 \mathrm{~h}+$ intermittent lighting + predator $24 \mathrm{~h}$ \\
\hline 48 & Water deprivation $10 \mathrm{~h}+$ cage tilt $24 \mathrm{~h}+$ day/night inversion \\
\hline 49 & Social isolation $8 \mathrm{~h}+$ noise $2 \mathrm{~h}+$ stroboscopic lighting $2 \mathrm{~h}$ \\
\hline 50 & Shaking $30 \mathrm{~min}+$ predator $24 \mathrm{~h}+$ darkness $24 \mathrm{~h}$ \\
\hline 51 & Strong smell + intermittent lighting + novelty stress \\
\hline 52 & Noise $6 \mathrm{~h}+$ crowding $12 \mathrm{~h}+$ sleep deprivation \\
\hline 53 & Swimming $30 \mathrm{~min}+$ flashing light $4 \mathrm{~h}+$ predator $24 \mathrm{~h}$ \\
\hline 54 & Social isolation $6 \mathrm{~h}+$ food deprivation $24 \mathrm{~h}+$ light $24 \mathrm{~h}$ \\
\hline 55 & Strong smell + novel objects $24 \mathrm{~h}+$ cage tilt $24 \mathrm{~h}$ \\
\hline 56 & Stroboscopic lighting $10 \mathrm{~h}+$ noise $5 \mathrm{~h}+$ day/night inversion \\
\hline 57 & Social isolation $8 \mathrm{~h}+$ food deprivation $24 \mathrm{u}+$ darkness $24 \mathrm{~h}$ \\
\hline 58 & Shaking $20 \mathrm{~min}+$ predator $24 \mathrm{~h}+$ flashing light $6 \mathrm{~h}$ \\
\hline 59 & Novel objects + intermittent lighting + water deprivation with empty bottle $24 \mathrm{~h}$ \\
\hline 60 & Strong smell + noise $6 \mathrm{~h}+$ novel objects $24 \mathrm{~h}$ \\
\hline 61 & Crowding $10 \mathrm{~h}+$ cage tilt $24 \mathrm{~h}+$ light $24 \mathrm{~h}$ \\
\hline 62 & Swimming $20 \mathrm{~min}+$ intermittent lighting + predator $24 \mathrm{~h}$ \\
\hline 63 & Water deprivation with empty bottle $12 \mathrm{~h}+$ strong smell + day/night inversion \\
\hline 64 & Social isolation $8 \mathrm{~h}+$ noise $8 \mathrm{~h}+$ food deprivation $24 \mathrm{~h}$ \\
\hline 65 & Flashing light $6 \mathrm{~h}+$ light $24 \mathrm{~h}+$ predator exposure $24 \mathrm{~h}$ \\
\hline 66 & Shaking $30 \mathrm{~min}+$ crowding $10 \mathrm{~h}$ \\
\hline 67 & Noise $2 \mathrm{~h}+$ stroboscopic lighting $6 \mathrm{~h}+$ cage tilt $24 \mathrm{~h}$ \\
\hline 68 & Predator $24 \mathrm{~h}+$ darkness $24 \mathrm{~h}$ with flashing light $(4 \mathrm{~h})$ \\
\hline 69 & Shaking $20 \mathrm{~min}+$ noise $8 \mathrm{~h}+$ novel objects $24 \mathrm{~h}$ \\
\hline 70 & Social isolation $8 \mathrm{~h}+$ intermittent lighting + food and water deprivation $24 \mathrm{~h}$ \\
\hline 71 & Swimming $20 \mathrm{~min}+$ predator $24 \mathrm{~h}+$ darkness $24 \mathrm{~h}$ \\
\hline 72 & Strong smell + novel objects $24 \mathrm{~h}+$ flashing light $10 \mathrm{~h}$ \\
\hline 73 & Social isolation $8 \mathrm{~h}+$ light $24 \mathrm{~h}$ \\
\hline 74 & Noise $8 \mathrm{~h}+$ intermittent lighting + food deprivation $24 \mathrm{~h}$ \\
\hline 75 & Crowding $10 \mathrm{~h}+$ shaking $30 \mathrm{~min}+$ predator exposure $24 \mathrm{~h}$ \\
\hline 76 & Water deprivation (with empty bottle) $12 \mathrm{~h}+$ cage tilt $24 \mathrm{~h}+$ day/night inversion \\
\hline 77 & Noise $6 \mathrm{~h}+$ stroboscopic lighting $8 \mathrm{~h}+$ sleep deprivation $24 \mathrm{~h}$ \\
\hline 78 & Predator $24 \mathrm{~h}$ +intermittent lighting $8 \mathrm{~h}$ \\
\hline 79 & Social isolation $8 \mathrm{~h}+$ strong smell $24 \mathrm{~h}+$ darkness $24 \mathrm{~h}$ \\
\hline 80 & Shaking $40 \mathrm{~min}+$ crowding $8 \mathrm{~h}$ \\
\hline 81 & Swimming $30 \mathrm{~min}+$ stroboscopic lighting with novel objects + noise $4 \mathrm{~h}$ \\
\hline 82 & Novelty stress + cage tilt $24 \mathrm{~h}+$ day/night inversion \\
\hline 83 & Social isolation $6 \mathrm{~h}+$ noise $6 \mathrm{~h}+$ sleep deprivation $24 \mathrm{~h}$ \\
\hline 84 & Flashing light in darkness $6 \mathrm{~h}+$ predator exposure $24 \mathrm{~h}$ \\
\hline 85 & Behavioral testing Day 1: grooming test (GT) \\
\hline 86 & Behavioral testing Day 2: the open field test (OF) \\
\hline 87 & Behavioral testing day 3: the elevated plus-maze test (EPMT) \\
\hline
\end{tabular}


bioRxiv preprint doi: https://doi.org/10.1101/2021.12.05.471274; this version posted December 7, 2021. The copyright holder for this preprint (which was not certified by peer review) is the author/funder, who has granted bioRxiv a license to display the preprint in perpetuity. It is made available under aCC-BY-NC-ND 4.0 International license.

$88 \quad$ Sacrificing the rats and collecting brain samples 
bioRxiv preprint doi: https://doi.org/10.1101/2021.12.05.471274; this version posted December 7, 2021. The copyright holder for this preprint (which was not certified by peer review) is the author/funder, who has granted bioRxiv a license to display the preprint in perpetuity. It is made available under aCC-BY-NC-ND 4.0 International license.

Table 2. Summary of PCUS manipulations used in the present study (see Table 1 for details)

\begin{tabular}{|c|c|c|}
\hline Stressors & Description & References \\
\hline Crowding & Twice increased cage density (to 8 rats per cage) & 155 \\
\hline Strong smell & $\begin{array}{l}\text { Sponge soaked with essential oil of lemon and bergamot placed } 5-10 \mathrm{~cm} \text { from the } \\
\text { home cage for } 24 \mathrm{~h} \text {. These essential oils were chosen based on their persistent } \\
\text { and pungent odor, known to be aversive for rats }\end{array}$ & 156 \\
\hline Novel objects & Two plastic toys $(6-13 \mathrm{~cm})$ placed into the homecage for $24 \mathrm{~h}$ & 157 \\
\hline Flashing light & 40-m flashing Christmas lights $(5 \mathrm{~Hz}, 150 \mathrm{Lx})$ placed on the top of homecages & 158 \\
\hline Water deprivation & Removing water bottle or placing empty bottle into the cage & 159,160 \\
\hline Food deprivation & Removing food from the feeder & 159,160 \\
\hline Shaking & $\begin{array}{l}\text { Rolling a cart }(100 \times 100 \times 150 \mathrm{~cm}) \text { with rat cages on an uneven surface at a } \\
\text { constant speed of } 6 \mathrm{~km} / \mathrm{h}\end{array}$ & 159 \\
\hline Swimming & $\begin{array}{l}\text { Rats individually placed in } 20-\mathrm{L} \text { plastic box filled with water }\left(22-24^{\circ}\right) \text { with legs } \\
\text { and tail not touching the bottom }\end{array}$ & 161 \\
\hline Novelty stress & $\begin{array}{l}\text { Rats individually placed into novel/unfamiliar plastic boxes }(39 \times 28 \times 28 \mathrm{~cm}, 56 \\
\mathrm{x} 39 \times 28 \mathrm{~cm} \text { or } 56 \times 39 \times 42 \mathrm{~cm}) \text { for } 5 \mathrm{~min}\end{array}$ & 66 \\
\hline $\begin{array}{l}\text { Day/night } \\
\text { inversion }\end{array}$ & Darkness in the morning and turning light on during the night & 159,160 \\
\hline Predator exposure & $\begin{array}{l}\text { The predator (cat) urine applied to a sponge and placed near the home cage (5-10 } \\
\mathrm{cm})\end{array}$ & 156 \\
\hline Darkness or light & Light or darkness in the animal homecages for 24 & 160 \\
\hline $\begin{array}{l}\text { Intermittent } \\
\text { lighting }\end{array}$ & Turning the lights on and off in the animal room every $2 \mathrm{~h}$ for $12 \mathrm{~h}$ & 160 \\
\hline Cage tilt & Cages individually tilted at a 45 -degree angle & 160,162 \\
\hline $\begin{array}{l}\text { Noise (drill } \\
\text { sound) }\end{array}$ & $\begin{array}{l}\text { A 50-db drill sound from an online video } \\
\text { www.youtube.com/watch?v=7Xomg2zge- } 8\end{array}$ & 163 \\
\hline Social isolation & Isolation of rats in a separate plastic box $(30 \times 20 \times 20 \mathrm{~cm})$ with bedding & 164 \\
\hline Sleep deprivation & $\begin{array}{l}\text { A cylindrical wooden plinth }(6 \mathrm{~cm} \text { in diameter and } 5 \mathrm{~cm} \text { in height }) \text { placed on the } \\
\text { floor of the cage opposite the food and water compartment. The cage is filled } \\
\text { with water }\left(22^{\circ}\right) \text { to a depth of } 3 \mathrm{~cm} \text {, allowing animals to stand, but not sit } \\
\text { comfortably or sleep }\end{array}$ & 165 \\
\hline $\begin{array}{l}\text { Stroboscopic } \\
\text { lights }\end{array}$ & $\begin{array}{l}\text { Flashing light ( } 160 \mathrm{Lx}) \text { exposure produced by a stroboscope at } 60 \text { flashes/min } 2 \\
\mathrm{~m} \text { from homecages }\end{array}$ & 160 \\
\hline
\end{tabular}


Table 3. Summary of the Wald Chi-square test results (ANOVA Type II) for generalized linear model (GZLM; Supplementary Table S1) using group, testing day and their interaction effects as 'predictors', to compare behavior of experimental rat groups (also see Supplementary Table S2 for Tukey test pair-wise Group comparison data). Note that while we used day, group and interaction to perform GZLM and ANOVA test, here we did not discuss day or interaction effects, and used them only to minimize any potential testing day effects on group factor in the models. Bolded text corresponds to significant ANOVA Type II treatment effects for corresponding endpoints $(\mathrm{p}<0.05$, ANOVA Type II).

\begin{tabular}{|c|c|c|c|c|c|c|}
\hline \multirow[b]{2}{*}{ Factor } & \multicolumn{2}{|c|}{ Open Field Test } & \multicolumn{2}{|c|}{ Elevated Plus-Maze Test } & \multicolumn{2}{|c|}{ Grooming Test } \\
\hline & Chisq & $\operatorname{Pr}(>$ Chisq $)$ & Chisq & $\operatorname{Pr}(>$ Chisq $)$ & Chisq & $\operatorname{Pr}(>$ Chisq $)$ \\
\hline & \multicolumn{2}{|c|}{ Freezing frequency, $\mathbf{n}$} & \multicolumn{2}{|c|}{ Closed Arm frequency, $n$} & \multicolumn{2}{|c|}{ Total grooming duration, $s$} \\
\hline Day & 10.02 & 0.88 & 6.17 & 0.013 & 11.03 & 0.0009 \\
\hline Group & $6 \mathbf{1 7 . 4 7}$ & 0.008 & 43.25 & $1.0366 e-07$ & 12.24 & 0.05 \\
\hline \multirow[t]{2}{*}{ Day:Group } & 614.51 & 0.024 & 10.80 & 0.09 & 9.80 & 0.12 \\
\hline & \multicolumn{2}{|c|}{ Freezing duration, $s$} & \multicolumn{2}{|c|}{ Open Arm frequency, $n$} & \multicolumn{2}{|c|}{ Rostral grooming duration, $s$} \\
\hline Day & 10.17 & 0.68 & 4.40 & 0.03 & 6.59 & 0.01 \\
\hline Group & 637.61 & $1.3363 \mathrm{e}-06$ & 8.61 & 0.19 & 8.88 & 0.18 \\
\hline \multirow[t]{2}{*}{ Day:Group } & 623.34 & 0.0007 & 10.05 & 0.12 & 8.72 & 0.18 \\
\hline & \multicolumn{2}{|c|}{ Rearing frequency, $n$} & \multicolumn{2}{|c|}{ Closed Arm duration, s } & \multicolumn{2}{|c|}{ Caudal grooming duration, $s$} \\
\hline Day & 11.78 & 0.18 & 4.26 & 0.04 & 25.89 & $3.6065 \mathrm{e}-07$ \\
\hline Group & 612.6 & 0.04 & 7.37 & 0.29 & 30.71 & $2.8833 e-05$ \\
\hline \multirow[t]{2}{*}{ Day:Group } & 610.15 & 0.12 & 12.17 & 0.06 & 14.38 & 0.026 \\
\hline & \multicolumn{2}{|c|}{ Rearing duration, $s$} & \multicolumn{2}{|c|}{ Open Arm duration, $\mathrm{s}$} & \multicolumn{2}{|c|}{ Paw licking duration, $\mathrm{s}$} \\
\hline Day & 10.66 & 0.41 & 62.2 & $3.0955 e-15$ & 1.05 & 0.31 \\
\hline Group & 615.01 & 0.02 & 67.56 & $1.2905 e-12$ & 8.77 & 0.19 \\
\hline \multirow[t]{2}{*}{ Day:Group } & 612.14 & 0.06 & 40.77 & $3.2092 \mathrm{e}-07$ & 9.25 & 0.16 \\
\hline & \multicolumn{2}{|c|}{ Climbing frequency, $n$} & \multicolumn{2}{|c|}{ Freezing frequency, $n$} & \multicolumn{2}{|c|}{ Nose grooming duration, $s$} \\
\hline Day & 13.99 & 0.05 & 10.24 & 0.0014 & 1.26 & 0.26 \\
\hline Group & 68.33 & 0.22 & 27.05 & 0.0001 & 5.07 & 0.53 \\
\hline \multirow[t]{2}{*}{ Day:Group } & 65.27 & 0.51 & 29.19 & $5.5877 \mathrm{e}-05$ & 9.6 & 0.14 \\
\hline & \multicolumn{2}{|c|}{ Climbing duration, $\mathrm{s}$} & \multicolumn{2}{|c|}{ Freezing duration, $\mathbf{s}$} & \multicolumn{2}{|c|}{ Head grooming duration, $s$} \\
\hline Day & 13.79 & 0.05 & 4.73 & 0.03 & 4.44 & 0.04 \\
\hline Group & 610.48 & 0.106 & 23.98 & 0.0005 & 66.84 & $1.8068 \mathrm{e}-12$ \\
\hline \multirow[t]{2}{*}{ Day:Group } & 65.95 & 0.43 & 11.54 & 0.07 & 13.47 & 0.04 \\
\hline & \multicolumn{2}{|c|}{ Vertical activity frequency, $n$} & & g latency, s & Bo & duration, $s$ \\
\hline Day & 10.25 & 0.62 & 8.32 & 0.004 & 55.78 & 8.117e-14 \\
\hline Group & 69.66 & 0.14 & 20.08 & 0.003 & 31.11 & $2.4145 \mathrm{e}-05$ \\
\hline Day:Group & 68.42 & 0.21 & 33.02 & $1.0374 \mathrm{e}-05$ & 14.28 & $\mathbf{0 . 0 3}$ \\
\hline & Verti & y duration, $s$ & & & & luration, $\mathrm{s}$ \\
\hline Day & 11.16 & 0.28 & & & 14.89 & 0.0001 \\
\hline Group & 610.92 & 0.09 & & & 37.28 & $1.5538 \mathrm{e}-06$ \\
\hline
\end{tabular}


bioRxiv preprint doi: https://doi.org/10.1101/2021.12.05.471274; this version posted December 7, 2021. The copyright holder for this preprint (which was not certified by peer review) is the author/funder, who has granted bioRxiv a license to display the preprint in perpetuity. It is made available under aCC-BY-NC-ND 4.0 International license.

\begin{tabular}{|c|c|c|c|c|}
\hline Day:Group & \begin{tabular}{l|l}
6 & 11.34 \\
\end{tabular} & 0.08 & 6.29 & 0.39 \\
\hline & & & \multicolumn{2}{|c|}{$\begin{array}{c}\text { Incorrect grooming transitions, } \\
\%\end{array}$} \\
\hline Day & 1 & & 3.13 & 0.08 \\
\hline Group & 6 & & 6.29 & 0.39 \\
\hline Day:Group & 6 & & 12.62 & 0.05 \\
\hline
\end{tabular}


Figure 1. Behavioral effects induced by prolonged chronic unpredictable stress (PCUS) exposure and fluoxetine, eicosapentaenoic acid (EPA) or lipopolysaccharide (LPS) treatment in rat assessed in the Open Field test. Data are presented as mean \pm SEM $(n=16-20) .{ }^{*} p<0.05$ vs. control, $\$ p<0.05$ vs. PCUS, post-hoc Tukey test for pair-wise comparison of significant Wald Chi-square $\left(\chi^{2}\right)$ analysis of variance (ANOVA Type II) for GZLM fits data. Graphs were constructed using the ggplot2 R package $^{166}$, also see Table 3 and Supplementary Tables S1-S2 for statistical details. C - control, S PCUS stress, F - fluoxetine, E - EPA, L - LPS groups.

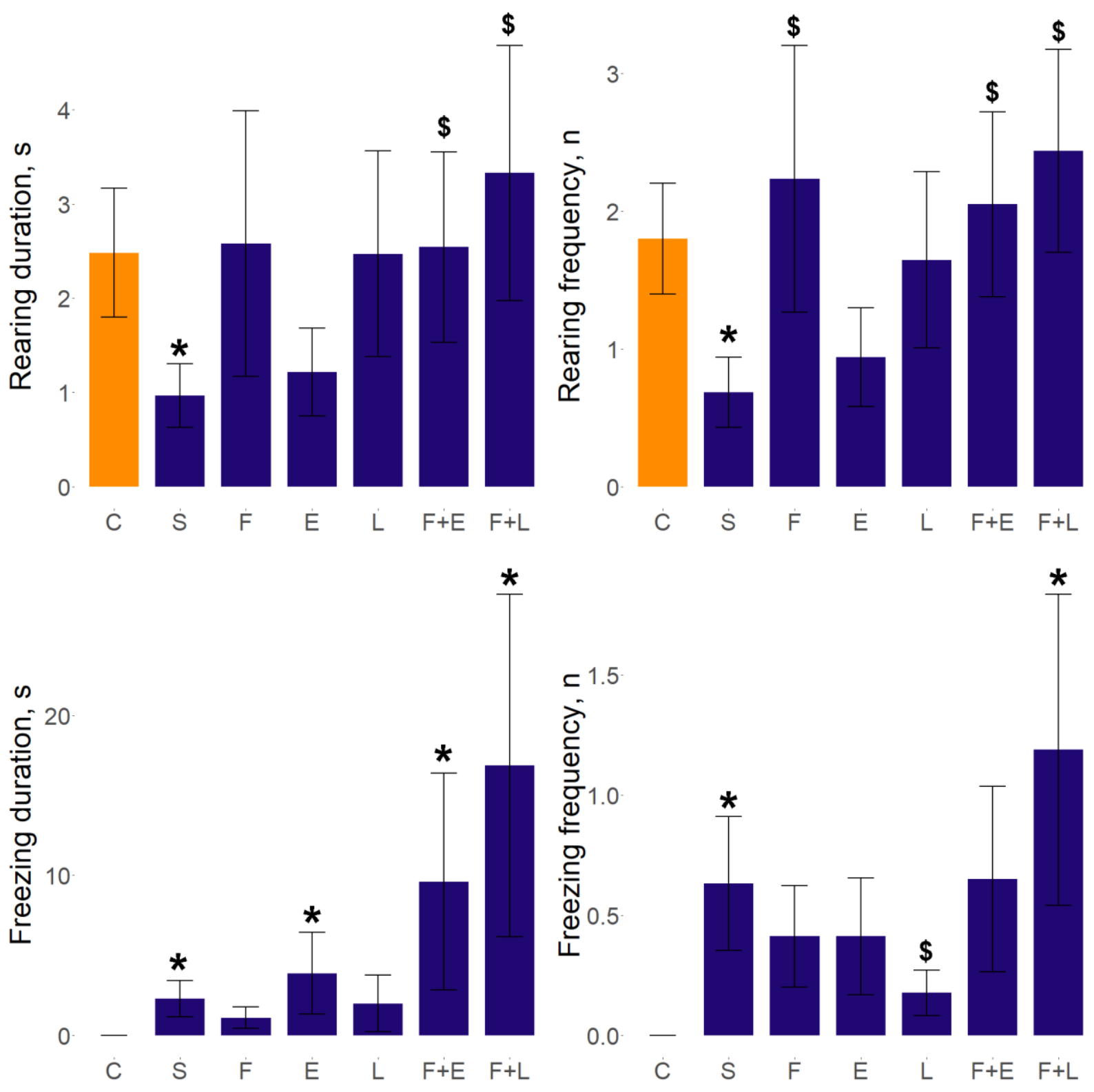


Figure 2. Behavioral effects induced by prolonged chronic unpredictable stress (PCUS) exposure and fluoxetine, eicosapentaenoic acid (EPA) or lipopolysaccharide (LPS) treatment in rat assessed in the Elevated plus-maze test. Data are presented as mean $\pm \operatorname{SEM}(n=15-20) .{ }^{*} p<0.05$ vs. control, $\$ p<0.05$ vs. CUS post-hoc Tukey test for pair-wise comparison of significant Wald chi-square $\left(\chi^{2}\right)$ analysis of variance (ANOVA Type II) for GZLM fits data. Graphs were constructed using the ggplot2 R package $^{166}$ also see Table 3 and Supplementary Tables S1-S2 for statistical details. C - control, S PCUS stress, F - fluoxetine, E - EPA, L - LPS groups.

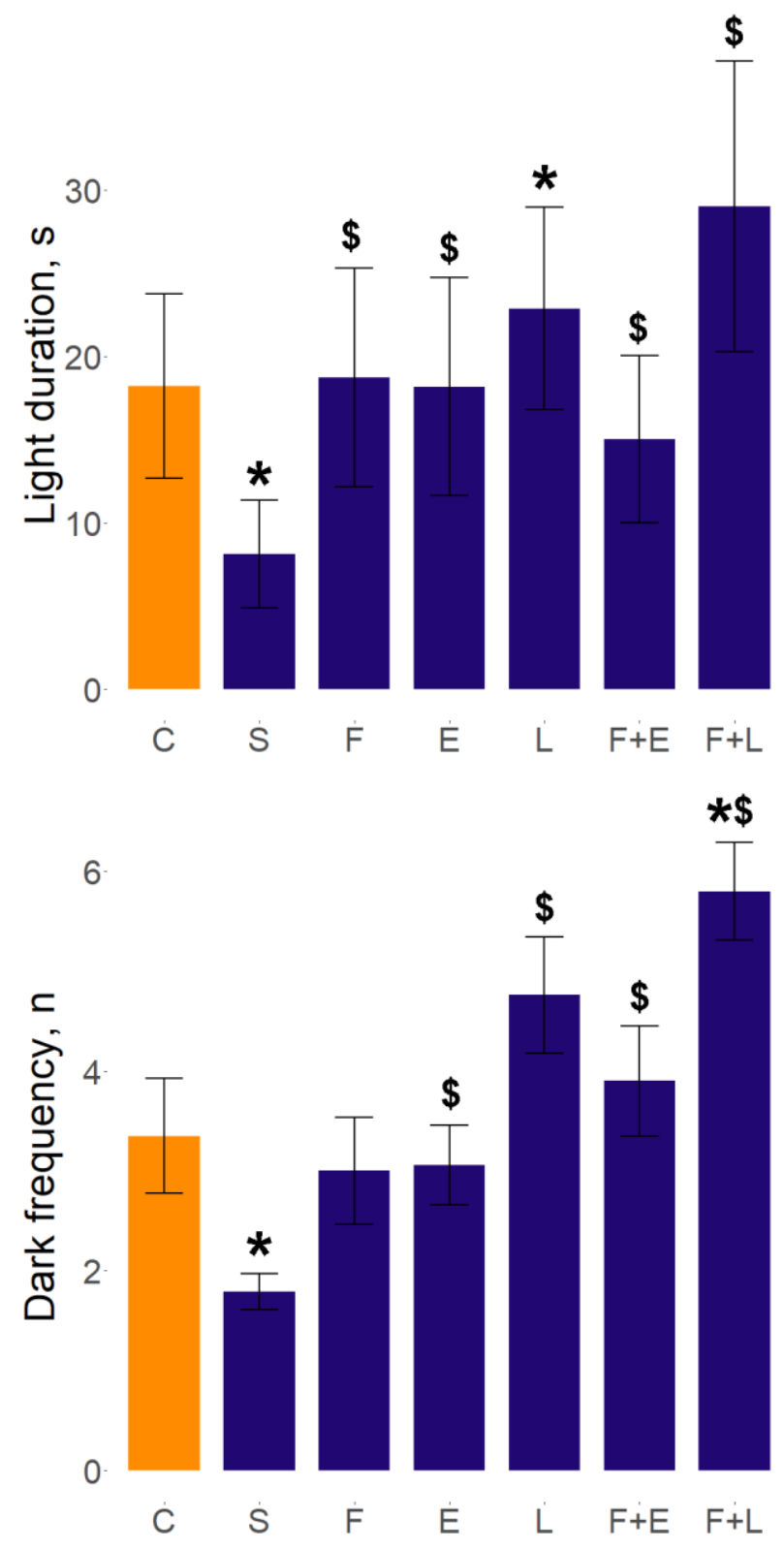


Figure 3. Behavioral effects induced by prolonged chronic unpredictable stress (PCUS) exposure and fluoxetine, eicosapentaenoic acid (EPA) or lipopolysaccharide (LPS) treatment in rat assessed in the grooming test. Data are presented as mean $\pm \operatorname{SEM}(n=15-20) .{ }^{*} \mathrm{p}<0.05$ vs. control, $\$ \mathrm{p}<0.05$ vs. CUS post-hoc Tukey test for pair-wise comparison of significant Wald chi-square $\left(\chi^{2}\right)$ analysis of variance (ANOVA Type II) for GZLM fits data. Graphs were constructed using the ggplot2 R package ${ }^{166}$, also see Table 3 and Supplementary Tables S1-S2 for statistical details and Supplementary Figure S4 for additional grooming analyses). C - control, S - PCUS stress, F - fluoxetine, E - EPA, L - LPS groups.
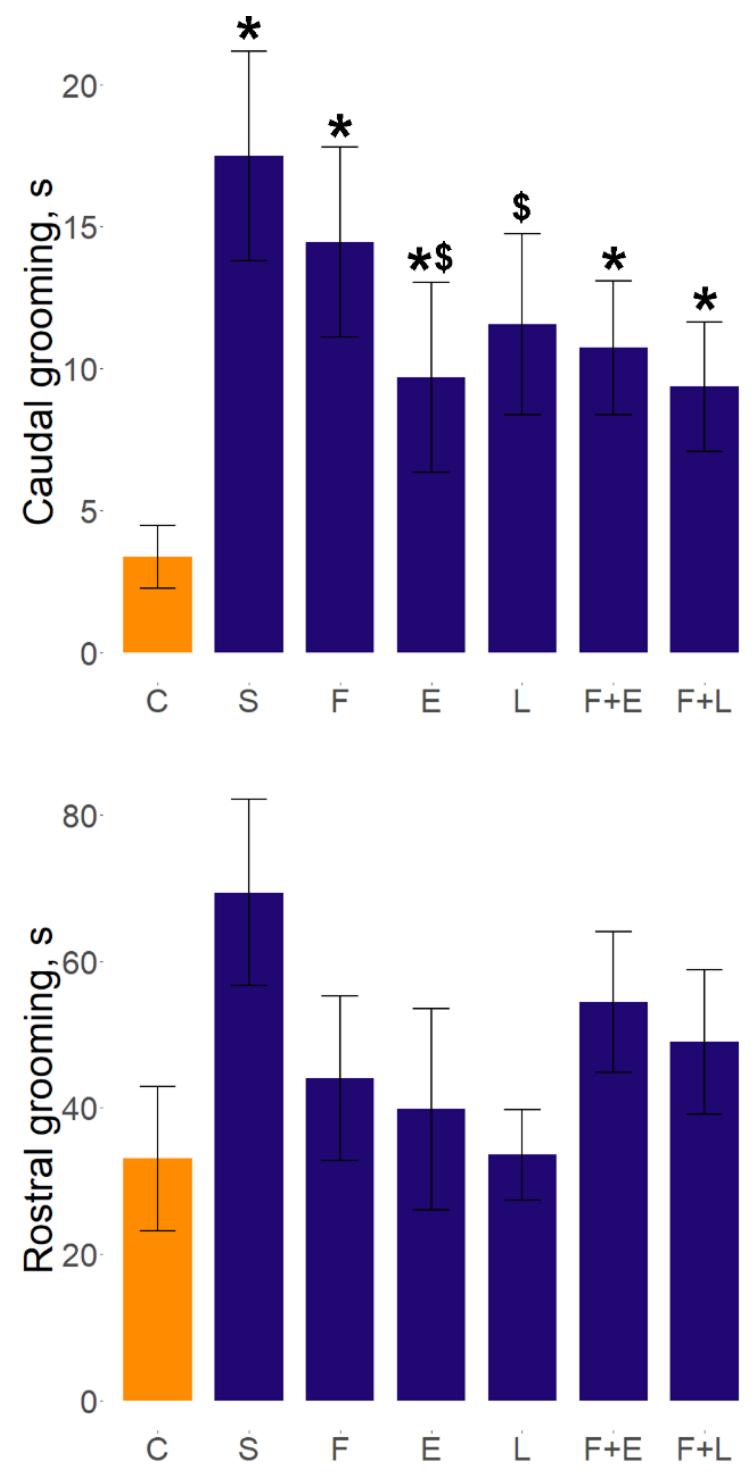
Figure 4. The top 10 up- or down-regulating genes in Principal Component 1-2 loadings based on

Principal Component Analyses (PCA). The 5-digit gene names correspond to the last 5 digits of

Ensembl ID for Rattus norvegicus (ENSRNOG000000*****).

Top loadings PC1
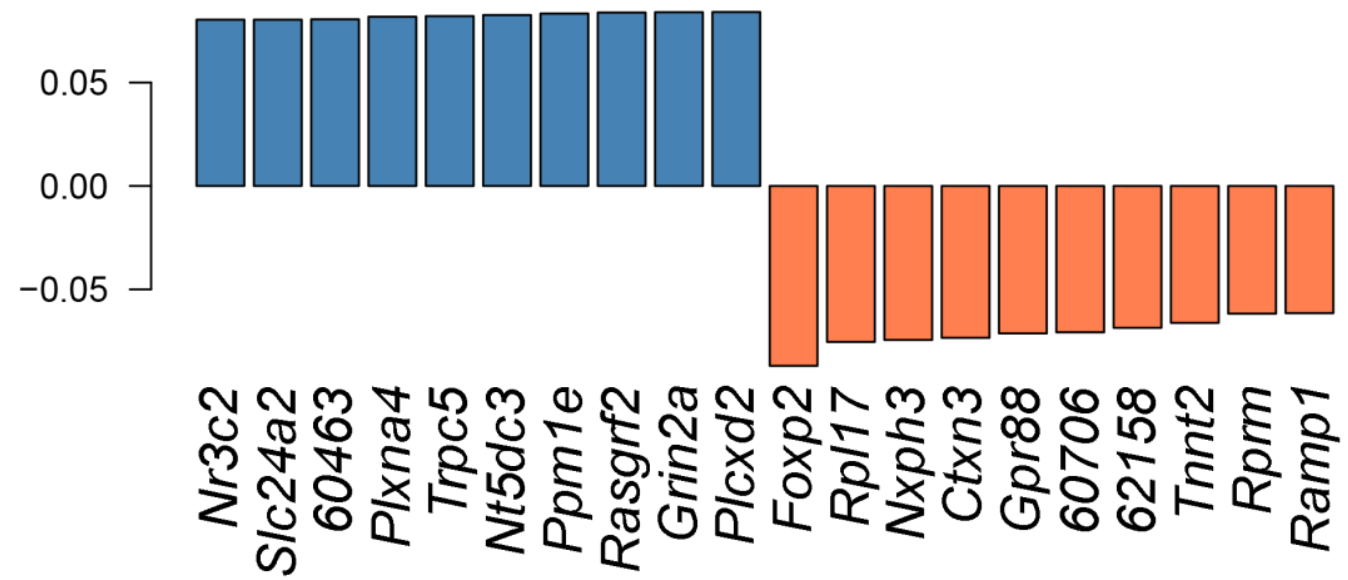

\section{Top loadings PC2}
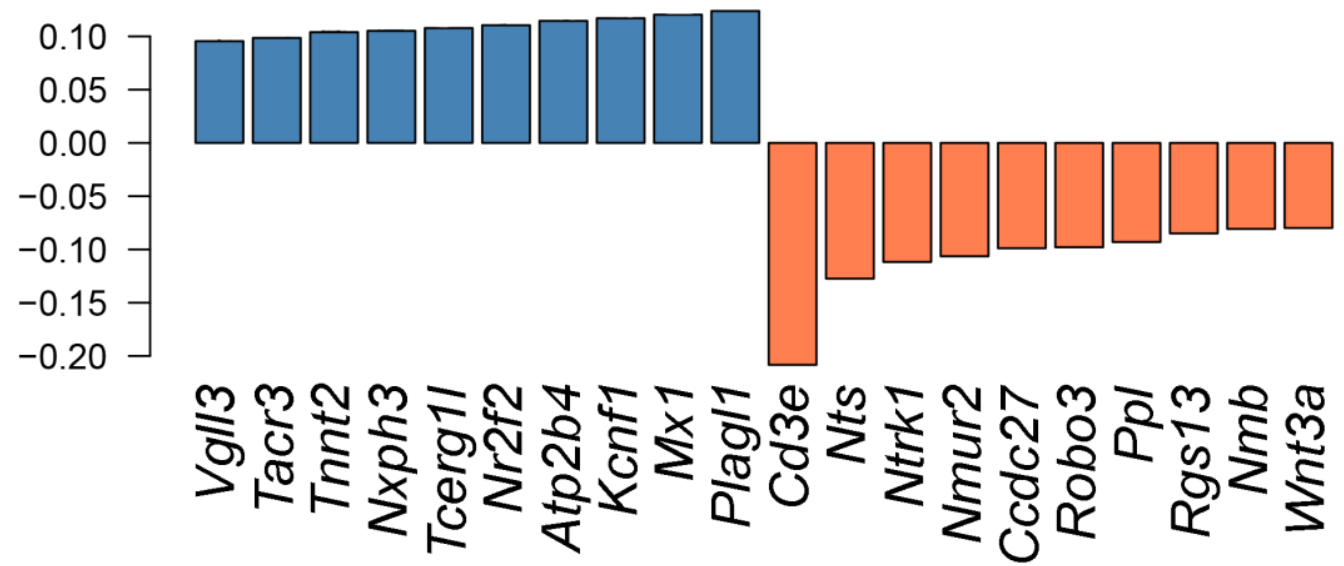
Figure 5. Venn's diagrams illustrating the relationship between differentially expressed (DE) genes in experimental vs. control rat group ( $q<0.016$ ) or vs. stress group ( $\mathrm{q}<0.02)$. PCUS - prolonged chronic unpredictable stress, FLU - fluoxetine, EPA - eicosapentaenoic acid, LPS - lipopolysaccharide. The numbers correspond to selected up- or down- regulated gene from the corresponding group overlaps. The diagrams were constructed using the VennDiagram R package ${ }^{93}$.

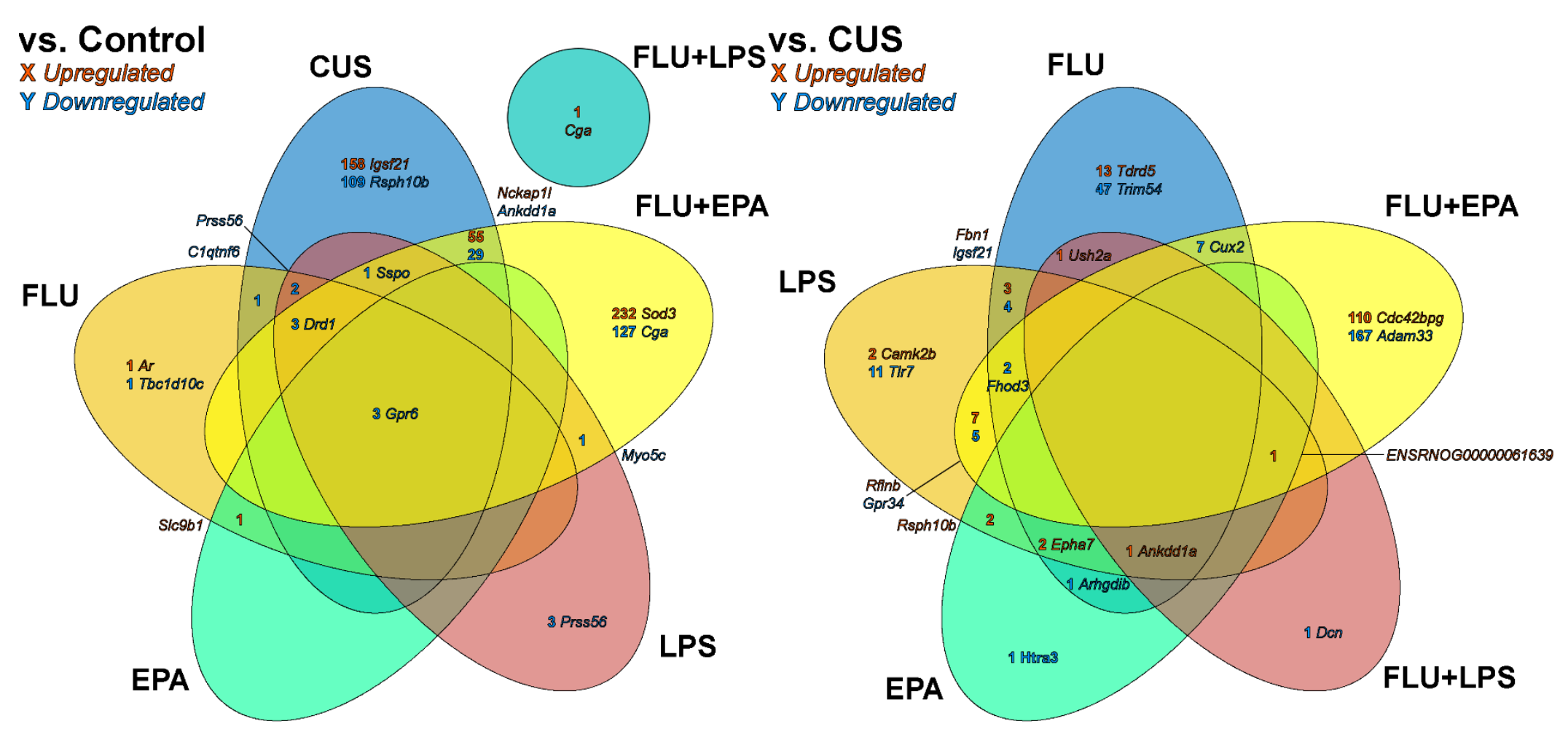


Figure 6. Venn's diagrams illustrating the relationship between differentially expressed (DE) KEGG sets of genes in experimental vs. control (q<0.016) or vs. stress rat groups $(\mathrm{q}<0.02)$. PCUS - prolonged chronic unpredictable stress, FLU - fluoxetine, EPA - eicosapentaenoic acid, LPS lipopolysaccharide. The numbers correspond to selected up- or down- regulated gene from the corresponding group overlaps. The diagrams were constructed using the VennDiagram R package ${ }^{93}$.

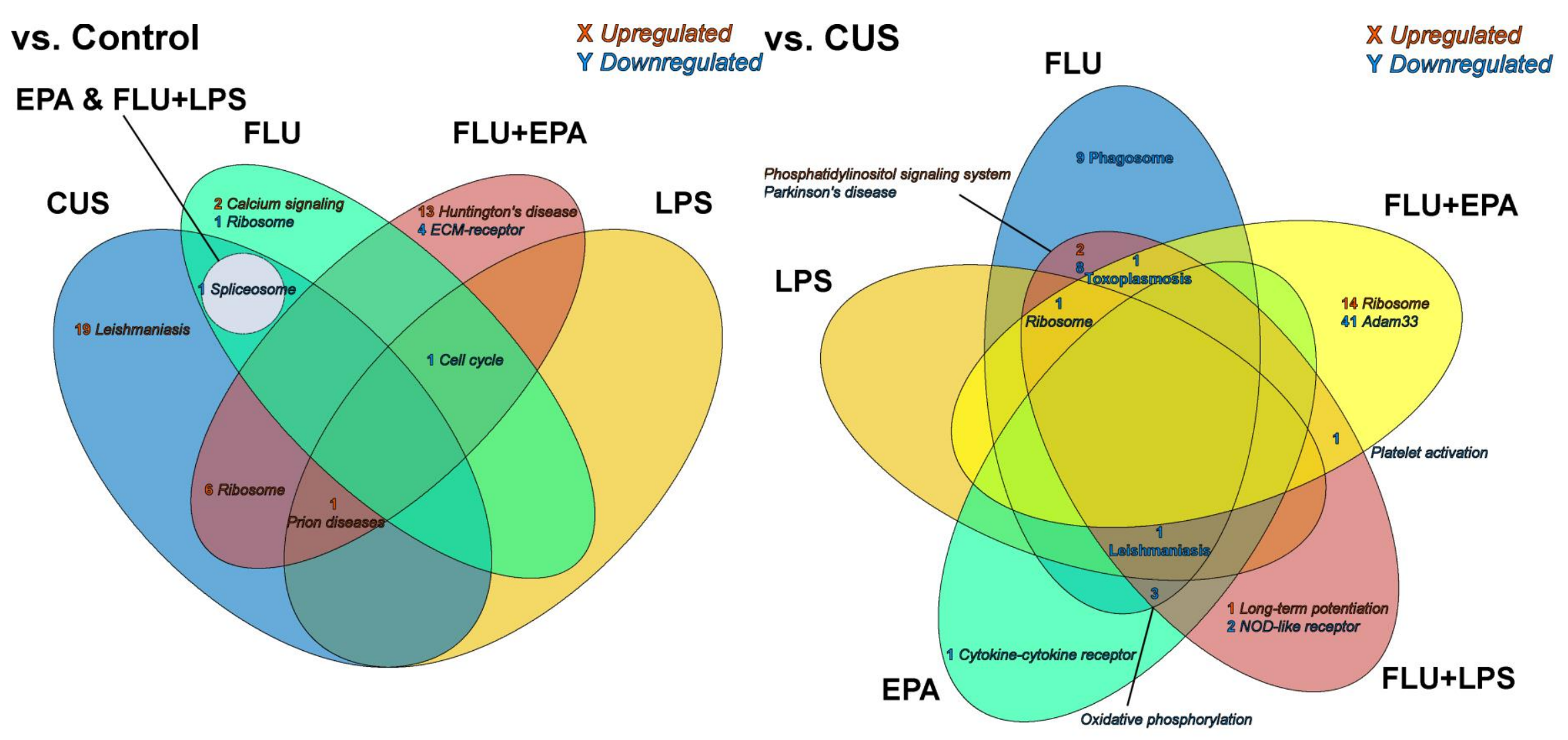




\section{CRediT authorship contribution statement}

Konstantin A. Demin (Conceptualization) (Data curation) (Formal analysis) (Funding acquisition) (Investigation) (Methodology) (Project administration) (Resources) (Software) (Validation)

(Visualization) (Writing - original draft) (Writing - review and editing), Tatiana O. Kolesnikova (Investigation) (Methodology) (Resources) (Data curation) (Formal analysis) (Writing - original draft) (Writing - review and editing), David S. Galstyan (Investigation) (Resources) (Data curation) (Writing - original draft) (Writing - review and editing), Nataliya A. Krotova (Investigation) (Writing - original draft) (Writing - review and editing), Nikita P. Ilyin (Investigation) (Writing - original draft) (Methodology) (Writing - review and editing), Ksenia A. Derzhavina (Investigation) (Writing original draft) (Methodology) (Writing - review and editing), Maria Seredinskaya (Investigation) (Writing - original draft) (Methodology) (Writing - review and editing), Yuriy M. Kositsyn (Investigation) (Writing - original draft) (Writing - review and editing), Dmitry V. Sorokin (Investigation) (Writing - original draft) (Writing - review and editing), Maria O. Nerush (Investigation) (Writing - original draft) (Writing - review and editing), Abubakar-Askhab S. Khaybaev (Investigation) (Writing - original draft) (Writing - review and editing), Sofia A. Pushkareva (Investigation) (Writing - original draft) (Writing - review and editing), Alexey Masharsky (Investigation) (Writing - original draft) (Writing - review and editing), Tatyana Strekalova (Writing - original draft) (Writing - review and editing), Allan V. Kalueff (Conceptualization) (Funding acquisition) (Methodology) (Project administration) (Resources) (Supervision) (Validation) (Visualization) (Writing - review and editing). 


\section{References:}

1 Elenkov, I. J., Wilder, R. L., Chrousos, G. P. \& Vizi, E. S. The sympathetic nerve - an integrative interface between two supersystems: the brain and the immune system. Pharmacological reviews 52, 595-638 (2000).

2 Russell, G. \& Lightman, S. The human stress response. Nature Reviews Endocrinology 15, 525-534 (2019).

3 McEwen, B. S. et al. Mechanisms of stress in the brain. Nature neuroscience 18, 1353-1363 (2015).

4 McEwen, B. S. Protective and damaging effects of stress mediators: central role of the brain. Dialogues in clinical neuroscience 8, 367 (2006).

5 McEwen, B. S. Physiology and neurobiology of stress and adaptation: central role of the brain. Physiological reviews 87, 873-904 (2007).

6 Sapolsky, R. M. The endocrine stress-response and social status in the wild baboon. Hormones and behavior 16, 279-292 (1982).

$7 \quad$ Walker, E., Mittal, V. \& Tessner, K. Stress and the hypothalamic pituitary adrenal axis in the developmental course of schizophrenia. Annu. Rev. Clin. Psychol. 4, 189-216 (2008).

8 Kyrou, I. \& Tsigos, C. Stress mechanisms and metabolic complications. Hormone and Metabolic Research 39, 430-438 (2007).

9 Elenkov, I. J. \& Chrousos, G. P. Stress hormones, proinflammatory and antiinflammatory cytokines, and autoimmunity. Annals of the New York Academy of Sciences 966, 290-303 (2002).

10 Golovatscka, V., Ennes, H., Mayer, E. A. \& Bradesi, S. Chronic stress-induced changes in pro-inflammatory cytokines and spinal glia markers in the rat: a time course study. Neuroimmunomodulation 19, 367-376 (2012).

11 Yang, P. et al. Changes in proinflammatory cytokines and white matter in chronically stressed rats. Neuropsychiatric disease and treatment 11, 597 (2015).

12 Charmandari, E., Tsigos, C. \& Chrousos, G. Endocrinology of the stress response. Annu. Rev. Physiol. 67, 259-284 (2005).

13 Chrousos, G. P. Stress and disorders of the stress system. Nature reviews endocrinology $\mathbf{5}$, 374 (2009).

14 Thomson, F. \& Craighead, M. Innovative approaches for the treatment of depression: targeting the HPA axis. Neurochemical Research 33, 691-707 (2008).

15 Barden, N. Implication of the hypothalamic-pituitary-adrenal axis in the physiopathology of depression. Journal of Psychiatry and Neuroscience 29, 185 (2004).

16 Bale, T. L. et al. The critical importance of basic animal research for neuropsychiatric disorders. Neuropsychopharmacology 44, 1349-1353 (2019).

17 Török, B., Sipos, E., Pivac, N. \& Zelena, D. Modelling posttraumatic stress disorders in animals. Progress in Neuro-Psychopharmacology and Biological Psychiatry 90, 117-133 (2019).

18 Meier, S. M. et al. Genetic variants associated with anxiety and stress-related disorders: a genome-wide association study and mouse-model study. JAMA psychiatry 76, 924-932 (2019).

19 Sandi, C. \& Richter-Levin, G. From high anxiety trait to depression: a neurocognitive hypothesis. Trends in neurosciences 32, 312-320 (2009).

20 Krishnan, V. \& Nestler, E. J. The molecular neurobiology of depression. Nature 455, 894902 (2008).

21 Sgoifo, A. \& Meerlo, P. Animal models of social stress: implications for the study of stress related pathologies in humans. Stress 5, 1-2 (2002).

22 Scharf, S. H. \& Schmidt, M. V. Animal models of stress vulnerability and resilience in translational research. Current Psychiatry Reports 14, 159-165 (2012).

23 Czéh, B., Fuchs, E., Wiborg, O. \& Simon, M. Animal models of major depression and their 
clinical implications. Progress in Neuro-Psychopharmacology and Biological Psychiatry 64, 293-310 (2016).

24 Bondi, C. O., Rodriguez, G., Gould, G. G., Frazer, A. \& Morilak, D. A. Chronic unpredictable stress induces a cognitive deficit and anxiety-like behavior in rats that is prevented by chronic antidepressant drug treatment. Neuropsychopharmacology 33, 320-331 (2008).

25 Cox, B. M., Alsawah, F., McNeill, P. C., Galloway, M. P. \& Perrine, S. A. Neurochemical, hormonal, and behavioral effects of chronic unpredictable stress in the rat. Behavioural brain research 220, 106-111 (2011).

26 Otabi, H., Goto, T., Okayama, T., Kohari, D. \& Toyoda, A. The acute social defeat stress and nest-building test paradigm: A potential new method to screen drugs for depressive-like symptoms. Behavioural processes 135, 71-75 (2017).

27 Monteiro, S. et al. An efficient chronic unpredictable stress protocol to induce stress-related responses in C57BL/6 mice. Frontiers in psychiatry 6, 6 (2015).

28 Ma, L. et al. Animal inflammation-based models of depression and their application to drug discovery. Expert opinion on drug discovery 12, 995-1009 (2017).

29 Willner, P. Validity, reliability and utility of the chronic mild stress model of depression: a 10-year review and evaluation. Psychopharmacology 134, 319-329 (1997).

30 Katz, R. J. Animal models and human depressive disorders. Neuroscience \& Biobehavioral Reviews 5, 231-246 (1981).

31 Katz, R. J. Animal model of depression: pharmacological sensitivity of a hedonic deficit. (1982).

32 Echandia, E. R., Gonzalez, A., Cabrera, R. \& Fracchia, L. A further analysis of behavioral and endocrine effects of unpredictable chronic stress. Physiology \& behavior 43, 789-795 (1988).

33 Mineur, Y. S., Belzung, C. \& Crusio, W. E. Effects of unpredictable chronic mild stress on anxiety and depression-like behavior in mice. Behavioural brain research 175, 43-50 (2006).

34 Paolo, S., Brain, P. \& Willner, P. Effects of chronic mild stress on performance in behavioural tests relevant to anxiety and depression. Physiology \& behavior 56, 861-867 (1994).

35 Hill, M. N., Hellemans, K. G., Verma, P., Gorzalka, B. B. \& Weinberg, J. Neurobiology of chronic mild stress: parallels to major depression. Neuroscience \& Biobehavioral Reviews 36, 2085-2117 (2012).

36 Harmer, C. J., Goodwin, G. M. \& Cowen, P. J. Why do antidepressants take so long to work? A cognitive neuropsychological model of antidepressant drug action. The British Journal of Psychiatry 195, 102-108 (2009).

37 Mitchell, A. J. Two-week delay in onset of action of antidepressants: new evidence. The British Journal of Psychiatry 188, 105-106 (2006).

38 Demin, K. A. et al. Modulation of behavioral and neurochemical responses of adult zebrafish by fluoxetine, eicosapentaenoic acid and lipopolysaccharide in the prolonged chronic unpredictable stress model. Scientific reports 11, 1-15 (2021).

39 Hubrecht, R. C. \& Kirkwood, J. The UFAW handbook on the care and management of laboratory and other research animals. (John Wiley \& Sons, 2010).

40 Beiko, J., Lander, R., Hampson, E., Boon, F. \& Cain, D. P. Contribution of sex differences in the acute stress response to sex differences in water maze performance in the rat. Behavioural brain research 151, 239-253 (2004).

41 Luine, V. Sex differences in chronic stress effects on memory in rats. Stress 5, 205-216 (2002).

42 Bowman, R. E., Beck, K. D. \& Luine, V. N. Chronic stress effects on memory: sex differences in performance and monoaminergic activity. Hormones and behavior 43, 48-59 (2003). 
43 Ter Horst, G. J., Wichmann, R., Gerrits, M., Westenbroek, C. \& Lin, Y. Sex differences in stress responses: focus on ovarian hormones. Physiology \& behavior 97, 239-249 (2009).

44 Henningsen, K. et al. Cognitive deficits in the rat chronic mild stress model for depression: relation to anhedonic-like responses. Behavioural brain research 198, 136-141 (2009).

45 Sanchez, C., Gruca, P. \& Papp, M. R-citalopram counteracts the antidepressant-like effect of escitalopram in a rat chronic mild stress model. Behavioural pharmacology 14, 465-470 (2003).

46 Chouinard, G. A double-blind controlled clinical trial of fluoxetine and amitriptyline in the treatment of outpatients with major depressive disorder. The Journal of clinical psychiatry 46, 32-37 (1985).

47 Bergstrom, R., Lemberger, L., Farid, N. \& Wolen, R. Clinical pharmacology and pharmacokinetics of fluoxetine: a review. The British Journal of Psychiatry 153, 47-50 (1988).

48 Cooper, G. L. The safety of fluoxetine-an update. The British Journal of Psychiatry 153, 7786 (1988).

49 Liu, X.-L. et al. Fluoxetine regulates mTOR signalling in a region-dependent manner in depression-like mice. Scientific reports 5, 1-11 (2015).

50 Nollet, M. et al. Activation of orexin neurons in dorsomedial/perifornical hypothalamus and antidepressant reversal in a rodent model of depression. Neuropharmacology 61, 336-346 (2011).

51 Christiansen, S., Olesen, M. V., Wörtwein, G. \& Woldbye, D. P. D. Fluoxetine reverts chronic restraint stress-induced depression-like behaviour and increases neuropeptide $\mathrm{Y}$ and galanin expression in mice. Behavioural brain research 216, 585-591 (2011).

52 Hodes, G. E., Hill-Smith, T. E. \& Lucki, I. Fluoxetine treatment induces dose dependent alterations in depression associated behavior and neural plasticity in female mice. Neuroscience letters 484, 12-16 (2010).

53 Rygula, R., Abumaria, N., Domenici, E., Hiemke, C. \& Fuchs, E. Effects of fluoxetine on behavioral deficits evoked by chronic social stress in rats. Behavioural brain research 174, 188-192 (2006).

54 Shen, Y., Connor, T. J., Nolan, Y., Kelly, J. P. \& Leonard, B. E. Differential effect of chronic antidepressant treatments on lipopolysaccharide-induced depressive-like behavioural symptoms in the rat. Life Sciences 65, 1773-1786 (1999).

55 Casaril, A. M. et al. Depression-and anxiogenic-like behaviors induced by lipopolysaccharide in mice are reversed by a selenium-containing indolyl compound: Behavioral, neurochemical and computational insights involving the serotonergic system. Journal of psychiatric research 115, 1-12 (2019).

56 Chang, D. et al. Effect of ketamine combined with DHA on lipopolysaccharide-induced depression-like behavior in rats. International immunopharmacology 75, 105788 (2019).

57 Mello, B. S. F. et al. Sex influences in behavior and brain inflammatory and oxidative alterations in mice submitted to lipopolysaccharide-induced inflammatory model of depression. Journal of neuroimmunology 320, 133-142 (2018).

58 Ji, M.-h. et al. Overinhibition mediated by parvalbumin interneurons might contribute to depression-like behavior and working memory impairment induced by lipopolysaccharide challenge. Behavioural brain research 383, 112509 (2020).

59 Liang, M. et al. Postnatal lipopolysaccharide exposure impairs adult neurogenesis and causes depression-like behaviors through astrocytes activation triggering GABAA receptor downregulation. Neuroscience 422, 21-31 (2019).

60 Kim, Y. J. \& Chung, H. Y. Antioxidative and anti-inflammatory actions of docosahexaenoic acid and eicosapentaenoic acid in renal epithelial cells and macrophages. Journal of medicinal food 10, 225-231 (2007).

61 Oshima, Y. et al. Effects of eicosapentaenoic acid and docosahexaenoic acid on anxiety-like behavior in socially isolated rats. Bioscience, biotechnology, and biochemistry 82, 716-723 
(2018).

62 Nobre, M. E. P. et al. Eicosapentaenoic acid and docosahexaenoic acid exert antiinflammatory and antinociceptive effects in rodents at low doses. Nutrition research $\mathbf{3 3}$, 422-433 (2013).

63 Pérez-Matute, P., Pérez-Echarri, N., Martínez, J. A., Marti, A. \& Moreno-Aliaga, M. J. Eicosapentaenoic acid actions on adiposity and insulin resistance in control and high-fat-fed rats: role of apoptosis, adiponectin and tumour necrosis factor- $\alpha$. British Journal of Nutrition 97, 389-398 (2007).

64 Horrobin, D. F., Lonergan, P. E., Martin, D. S. \& Lynch, M. A. Neuroprotective effect of eicosapentaenoic acid in hippocampus of rats exposed to $\gamma$-irradiation. Journal of Biological Chemistry 277, 20804-20811 (2002).

65 Walsh, R. N. \& Cummins, R. A. The open-field test: a critical review. Psychological bulletin 83, 482 (1976).

66 Hall, C. S. Emotional behavior in the rat. III. The relationship between emotionality and ambulatory activity. Journal of Comparative Psychology 22, 345 (1936).

67 Pellow, S. \& File, S. E. Anxiolytic and anxiogenic drug effects on exploratory activity in an elevated plus-maze: a novel test of anxiety in the rat. Pharmacology biochemistry and behavior 24, 525-529 (1986).

68 Kalueff, A. V. \& Tuohimaa, P. Mouse grooming microstructure is a reliable anxiety marker bidirectionally sensitive to GABAergic drugs. European journal of pharmacology 508, 147 153 (2005).

69 Smolinsky, A. N., Bergner, C. L., LaPorte, J. L. \& Kalueff, A. V. in Mood and anxiety related phenotypes in mice 21-36 (Springer, 2009).

70 Denmark, A. et al. The effects of chronic social defeat stress on mouse self-grooming behavior and its patterning. Behavioural brain research 208, 553-559 (2010).

71 Kalueff, A. V. \& Tuohimaa, P. Grooming analysis algorithm for neurobehavioural stress research. Brain Research Protocols 13, 151-158 (2004).

72 Kalueff, A. V. \& Tuohimaa, P. The grooming analysis algorithm discriminates between different levels of anxiety in rats: potential utility for neurobehavioural stress research. Journal of neuroscience methods 143, 169-177 (2005).

73 Kalueff, A. V., Aldridge, J. W., LaPorte, J. L., Murphy, D. L. \& Tuohimaa, P. Analyzing grooming microstructure in neurobehavioral experiments. Nature protocols 2, 2538 (2007).

74 Demin, K. A. et al. Understanding complex dynamics of behavioral, neurochemical and transcriptomic changes induced by prolonged chronic unpredictable stress in zebrafish. Scientific reports 10, 1-20 (2020).

75 Casals, M., Girabent-Farres, M. \& Carrasco, J. L. Methodological quality and reporting of generalized linear mixed models in clinical medicine (2000-2012): a systematic review. PloS one 9 (2014).

76 McCullagh, P. Generalized linear models. (Routledge, 2018).

77 Dobson, A. J. \& Barnett, A. G. An introduction to generalized linear models. (CRC press, 2018).

78 Liu, C., Cripe, T. P. \& Kim, M.-O. Statistical issues in longitudinal data analysis for treatment efficacy studies in the biomedical sciences. Molecular Therapy 18, 1724-1730 (2010).

79 Diggle, P. et al. Analysis of longitudinal data. (Oxford University Press, 2002).

80 Nelder, J. A. \& Wedderburn, R. W. Generalized linear models. Journal of the Royal Statistical Society: Series A (General) 135, 370-384 (1972).

81 Burnham, K. P. \& Anderson, D. R. Multimodel inference: understanding AIC and BIC in model selection. Sociological methods \& research 33, 261-304 (2004).

82 Akaike, H. A new look at the statistical model identification. IEEE transactions on automatic control 19, 716-723 (1974).

83 Motulsky, H. \& Christopoulos, A. Fitting models to biological data using linear and 


\section{R Core Team. (2017).}

85 Wang, D. et al. Behavioral and physiological effects of acute and chronic kava exposure in adult zebrafish. Neurotoxicology and Teratology, 106881 (2020).

86 Dobin, A. et al. STAR: ultrafast universal RNA-seq aligner. Bioinformatics 29, 15-21 (2013).

87 Liao, Y., Smyth, G. K. \& Shi, W. featureCounts: an efficient general purpose program for assigning sequence reads to genomic features. Bioinformatics 30, 923-930 (2014).

88 Huber, W. et al. Orchestrating high-throughput genomic analysis with Bioconductor. Nat Meth 12, 115-121, doi:10.1038/nmeth.3252 (2015).

89 Love, M. I., Huber, W. \& Anders, S. Moderated estimation of fold change and dispersion for RNA-seq data with DESeq2. Genome Biology 15, 550, doi:10.1186/s13059-014-0550-8 (2014).

90 Schurch, N. J. et al. How many biological replicates are needed in an RNA-seq experiment and which differential expression tool should you use? RNA 22, 839-851, doi:10.1261/rna.053959.115 (2016).

91 Marini, F. \& Binder, H. pcaExplorer: an R/Bioconductor package for interacting with RNAseq principal components. BMC bioinformatics 20, 1-8 (2019).

92 Love, M. I., Anders, S. \& Huber, W. (2019).

93 Chen, H. \& Boutros, P. C. VennDiagram: a package for the generation of highlycustomizable Venn and Euler diagrams in R. BMC bioinformatics 12, 1-7 (2011).

94 Subramanian, A. et al. Gene set enrichment analysis: a knowledge-based approach for interpreting genome-wide expression profiles. Proceedings of the National Academy of Sciences 102, 15545-15550 (2005).

95 Kim, S.-Y. \& Volsky, D. J. PAGE: parametric analysis of gene set enrichment. BMC bioinformatics 6, 144 (2005).

96 Nam, D. \& Kim, S.-Y. Gene-set approach for expression pattern analysis. Briefings in bioinformatics 9, 189-197 (2008).

97 Tian, L. et al. Discovering statistically significant pathways in expression profiling studies. Proceedings of the National Academy of Sciences 102, 13544-13549 (2005).

98 Luo, W., Friedman, M. S., Shedden, K., Hankenson, K. D. \& Woolf, P. J. GAGE: generally applicable gene set enrichment for pathway analysis. BMC Bioinformatics 10, 161, doi:10.1186/1471-2105-10-161 (2009).

99 Normandeau, C. P. et al. A key role for neurotensin in chronic-stress-induced anxiety-like behavior in rats. Neuropsychopharmacology 43, 285-293 (2018).

100 Wang, Y.-L. et al. Microglial activation mediates chronic mild stress-induced depressive-and anxiety-like behavior in adult rats. Journal of neuroinflammation 15, 1-14 (2018).

101 Patriquin, M. A. \& Mathew, S. J. The neurobiological mechanisms of generalized anxiety disorder and chronic stress. Chronic Stress 1, 2470547017703993 (2017).

102 Zhang, C., Kalueff, A. V. \& Song, C. Minocycline ameliorates anxiety-related self-grooming behaviors and alters hippocampal neuroinflammation, GABA and serum cholesterol levels in female Sprague-Dawley rats subjected to chronic unpredictable mild stress. Behavioural brain research 363, 109-117 (2019).

103 Baldwin, D., Woods, R., Lawson, R. \& Taylor, D. Efficacy of drug treatments for generalised anxiety disorder: systematic review and meta-analysis. Bmj 342, d1199 (2011).

104 Greenberg, R. P., Bornstein, R. F., Zborowski, M. J., Fisher, S. \& Greenberg, M. D. A metaanalysis of fluoxetine outcome in the treatment of depression. Journal of Nervous and Mental Disease (1994).

105 Sacre, S., Medghalchi, M., Gregory, B., Brennan, F. \& Williams, R. Fluoxetine and citalopram exhibit potent antiinflammatory activity in human and murine models of rheumatoid arthritis and inhibit toll - like receptors. Arthritis \& Rheumatism 62, 683-693 (2010). 
bioRxiv preprint doi: https://doi.org/10.1101/2021.12.05.471274; this version posted December 7, 2021. The copyright holder for this preprint (which was not certified by peer review) is the author/funder, who has granted bioRxiv a license to display the preprint in perpetuity. It is made available under aCC-BY-NC-ND 4.0 International license.

106 Lapmanee, S., Charoenphandhu, J. \& Charoenphandhu, N. Beneficial effects of fluoxetine, reboxetine, venlafaxine, and voluntary running exercise in stressed male rats with anxietyand depression-like behaviors. Behavioural brain research 250, 316-325 (2013).

107 Sun, Y., Evans, J., Russell, B., Kydd, R. \& Connor, B. A benzodiazepine impairs the neurogenic and behavioural effects of fluoxetine in a rodent model of chronic stress. Neuropharmacology 72, 20-28 (2013).

108 Kumar, J. et al. Differential effects of chronic social stress and fluoxetine on meal patterns in mice. Appetite 64, 81-88 (2013).

109 Mozaffari-Khosravi, H., Yassini-Ardakani, M., Karamati, M. \& Shariati-Bafghi, S.-E. Eicosapentaenoic acid versus docosahexaenoic acid in mild-to-moderate depression: a randomized, double-blind, placebo-controlled trial. European Neuropsychopharmacology 23, 636-644 (2013).

110 Sublette, M. E., Ellis, S. P., Geant, A. L. \& Mann, J. J. Meta-analysis: effects of eicosapentaenoic acid in clinical trials in depression. The Journal of clinical psychiatry $\mathbf{7 2}$, 1577 (2011).

111 Jazayeri, S. et al. Comparison of therapeutic effects of omega-3 fatty acid eicosapentaenoic acid and fluoxetine, separately and in combination, in major depressive disorder. Australian \& New Zealand Journal of Psychiatry 42, 192-198 (2008).

112 Yucel, G. et al. Lipopolysaccharides induced inflammatory responses and electrophysiological dysfunctions in human-induced pluripotent stem cell derived cardiomyocytes. Sci Rep 7, 2935, doi:10.1038/s41598-017-03147-4 (2017).

113 Connor, T. J., Harkin, A., Kelly, J. P. \& Leonard, B. E. Olfactory bulbectomy provokes a suppression of interleukin-1 beta and tumour necrosis factor-alpha production in response to an in vivo challenge with lipopolysaccharide: effect of chronic desipramine treatment. Neuroimmunomodulation 7, 27-35, doi:10.1159/000026417 (2000).

114 van Heesch, F. et al. Systemic tumor necrosis factor-alpha decreases brain stimulation reward and increases metabolites of serotonin and dopamine in the nucleus accumbens of mice. Behav Brain Res 253, 191-195, doi:10.1016/j.bbr.2013.07.038 (2013).

115 Chapkin, R. S., Kim, W., Lupton, J. R. \& McMurray, D. N. Dietary docosahexaenoic and eicosapentaenoic acid: emerging mediators of inflammation. Prostaglandins Leukot Essent Fatty Acids 81, 187-191, doi:10.1016/j.plefa.2009.05.010 (2009).

116 Augimeri, G. et al. N-Eicosapentaenoyl Dopamine, A Conjugate of Dopamine and Eicosapentaenoic Acid (EPA), Exerts Anti-inflammatory Properties in Mouse and Human Macrophages. Nutrients 11, doi:10.3390/nu11092247 (2019).

117 Frynta, D. et al. Behavioural strategies of three wild-derived populations of the house mouse (Mus m. musculus and M. m. domesticus) in five standard tests of exploration and boldness: searching for differences attributable to subspecies and commensalism. Behavioural processes 157, 133-141 (2018).

118 Clipperton-Allen, A. E. et al. Oxytocin, vasopressin and estrogen receptor gene expression in relation to social recognition in female mice. Physiology \& behavior 105, 915-924 (2012).

119 Volgin, A. D. et al. Zebrafish models for personalized psychiatry: Insights from individual, strain and sex differences, and modeling gene x environment interactions. Journal of Neuroscience Research 97, 402-413 (2019).

120 Faraday, M. M. Rat sex and strain differences in responses to stress. Physiology \& behavior 75, 507-522 (2002).

121 Rosecrans, J. A. Differences in brain area 5-hydroxytryptamine turnover and rearing behavior in rats and mice of both sexes. European journal of pharmacology 9, 379-382 (1970).

122 Bowman, R. E., Maclusky, N. J., Diaz, S. E., Zrull, M. C. \& Luine, V. N. Aged rats: sex differences and responses to chronic stress. Brain research 1126, 156-166 (2006).

123 Ehrlich, A. T. et al. Expression map of 78 brain-expressed mouse orphan GPCRs provides a 
bioRxiv preprint doi: https://doi.org/10.1101/2021.12.05.471274; this version posted December 7, 2021. The copyright holder for this preprint (which was not certified by peer review) is the author/funder, who has granted bioRxiv a license to display the preprint in perpetuity. It is made available under aCC-BY-NC-ND 4.0 International license.

translational resource for neuropsychiatric research. Commun Biol 1, 102, doi:10.1038/s42003-018-0106-7 (2018).

124 Nicol, L. S. et al. The role of G-protein receptor 84 in experimental neuropathic pain. $J$ Neurosci 35, 8959-8969, doi:10.1523/JNEUROSCI.3558-14.2015 (2015).

125 Khan, M. Z. \& He, L. Neuro-psychopharmacological perspective of Orphan receptors of Rhodopsin (class A) family of G protein-coupled receptors. Psychopharmacology (Berl) 234, 1181-1207, doi:10.1007/s00213-017-4586-9 (2017).

126 Doi, M. et al. Gpr176 is a Gz-linked orphan G-protein-coupled receptor that sets the pace of circadian behaviour. Nat Commun 7, 10583, doi:10.1038/ncomms10583 (2016).

127 Uhlenbrock, K., Gassenhuber, H. \& Kostenis, E. Sphingosine 1-phosphate is a ligand of the human gpr3, gpr6 and gpr12 family of constitutively active $\mathrm{G}$ protein-coupled receptors. Cellular signalling 14, 941-953 (2002).

128 Lobo, M. K., Cui, Y., Ostlund, S. B., Balleine, B. W. \& Yang, X. W. Genetic control of instrumental conditioning by striatopallidal neuron-specific S1P receptor Gpr6. Nat Neurosci 10, 1395-1397, doi:10.1038/nn1987 (2007).

129 Tanaka, S., Ishii, K., Kasai, K., Yoon, S. O. \& Saeki, Y. Neural expression of G proteincoupled receptors GPR3, GPR6, and GPR12 up-regulates cyclic AMP levels and promotes neurite outgrowth. J Biol Chem 282, 10506-10515, doi:10.1074/jbc.M700911200 (2007).

130 Komatsu, H. Novel Therapeutic GPCRs for Psychiatric Disorders. Int J Mol Sci 16, 1410914121, doi:10.3390/ijms160614109 (2015).

131 Gingrich, B., Liu, Y., Cascio, C., Wang, Z. \& Insel, T. R. Dopamine D2 receptors in the nucleus accumbens are important for social attachment in female prairie voles (Microtus ochrogaster). Behav Neurosci 114, 173-183, doi:10.1037//0735-7044.114.1.173 (2000).

132 Shively, C. A., Grant, K. A., Ehrenkaufer, R. L., Mach, R. H. \& Nader, M. A. Social stress, depression, and brain dopamine in female cynomolgus monkeys. Ann N Y Acad Sci 807, 574-577, doi:10.1111/j.1749-6632.1997.tb51972.x (1997).

133 Schneier, F. R. et al. Low dopamine $\mathrm{D}(2)$ receptor binding potential in social phobia. Am J Psychiatry 157, 457-459, doi:10.1176/appi.ajp.157.3.457 (2000).

134 Klimek, V., Schenck, J. E., Han, H., Stockmeier, C. A. \& Ordway, G. A. Dopaminergic abnormalities in amygdaloid nuclei in major depression: a postmortem study. Biol Psychiatry 52, 740-748, doi:10.1016/s0006-3223(02)01383-5 (2002).

135 Cunha, R. A., Ferre, S., Vaugeois, J. M. \& Chen, J. F. Potential therapeutic interest of adenosine A2A receptors in psychiatric disorders. Curr Pharm Des 14, 1512-1524, doi:10.2174/138161208784480090 (2008).

136 Morelli, M. et al. Role of adenosine A2A receptors in parkinsonian motor impairment and 1DOPA-induced motor complications. Prog Neurobiol 83, 293-309, doi:10.1016/j.pneurobio.2007.07.001 (2007).

137 Tanabe, Y. et al. IgSF21 promotes differentiation of inhibitory synapses via binding to neurexin2alpha. Nat Commun 8, 408, doi:10.1038/s41467-017-00333-w (2017).

138 Cohen, J. L. et al. Differential stress induced c-Fos expression and identification of regionspecific miRNA-mRNA networks in the dorsal raphe and amygdala of high-responder/lowresponder rats. Behav Brain Res 319, 110-123, doi:10.1016/j.bbr.2016.11.015 (2017).

139 Zhao, D. et al. Prenatal stress disturbs hippocampal KIF17 and NR2B in spatial cognition in male offspring. J Neurosci Res 91, 535-544, doi:10.1002/jnr.23172 (2013).

140 Setou, M., Nakagawa, T., Seog, D. H. \& Hirokawa, N. Kinesin superfamily motor protein KIF17 and mLin-10 in NMDA receptor-containing vesicle transport. Science 288, 17961802, doi:10.1126/science.288.5472.1796 (2000).

141 Guo, X. et al. Chronic mild restraint stress rats decreased CMKLR1 expression in distinct brain region. Neurosci Lett 524, 25-29, doi:10.1016/j.neulet.2012.06.075 (2012).

142 Knight, A. K. et al. SLC9B1 methylation predicts fetal intolerance of labor. Epigenetics 13, 33-39, doi:10.1080/15592294.2017.1411444 (2018).

143 Klengel, T., Pape, J., Binder, E. B. \& Mehta, D. The role of DNA methylation in stress- 
bioRxiv preprint doi: https://doi.org/10.1101/2021.12.05.471274; this version posted December 7, 2021. The copyright holder for this preprint (which was not certified by peer review) is the author/funder, who has granted bioRxiv a license to display the preprint in perpetuity. It is made available under aCC-BY-NC-ND 4.0 International license.

related psychiatric disorders. Neuropharmacology 80, 115-132, doi:10.1016/j.neuropharm.2014.01.013 (2014).

144 Januar, V., Saffery, R. \& Ryan, J. Epigenetics and depressive disorders: a review of current progress and future directions. Int J Epidemiol 44, 1364-1387, doi:10.1093/ije/dyu273 (2015).

145 Bakusic, J., Schaufeli, W., Claes, S. \& Godderis, L. Stress, burnout and depression: A systematic review on DNA methylation mechanisms. J Psychosom Res 92, 34-44, doi:10.1016/j.jpsychores.2016.11.005 (2017).

146 Jazayeri, S. et al. Comparison of therapeutic effects of omega-3 fatty acid eicosapentaenoic acid and fluoxetine, separately and in combination, in major depressive disorder. Aust NZJ Psychiatry 42, 192-198, doi:10.1080/00048670701827275 (2008).

147 Jazayeri, S. et al. Effects of eicosapentaenoic acid and fluoxetine on plasma cortisol, serum interleukin-1beta and interleukin-6 concentrations in patients with major depressive disorder. Psychiatry Res 178, 112-115, doi:10.1016/j.psychres.2009.04.013 (2010).

148 Kemp, K., Gray, E., Mallam, E., Scolding, N. \& Wilkins, A. Inflammatory cytokine induced regulation of superoxide dismutase 3 expression by human mesenchymal stem cells. Stem Cell Rev Rep 6, 548-559, doi:10.1007/s12015-010-9178-6 (2010).

149 Miskic, T., Kostovic, I., Rasin, M. R. \& Krsnik, Z. Adult Upper Cortical Layer Specific Transcription Factor CUX2 Is Expressed in Transient Subplate and Marginal Zone Neurons of the Developing Human Brain. Cells 10, doi:10.3390/cells10020415 (2021).

150 Jacobsen, N. J. et al. CUX2, a potential regulator of NCAM expression: genomic characterization and analysis as a positional candidate susceptibility gene for bipolar disorder. Am J Med Genet 105, 295-300, doi:10.1002/ajmg.1325 (2001).

151 Hung, Y. F., Chen, C. Y., Li, W. C., Wang, T. F. \& Hsueh, Y. P. Tlr7 deletion alters expression profiles of genes related to neural function and regulates mouse behaviors and contextual memory. Brain Behav Immun 72, 101-113, doi:10.1016/j.bbi.2018.06.006 (2018).

152 Novak, G., Seeman, P. \& Tallerico, T. Increased expression of calcium/calmodulindependent protein kinase IIbeta in frontal cortex in schizophrenia and depression. Synapse 59, 61-68, doi:10.1002/syn.20211 (2006).

153 Demin, K. A. et al. CNS genomic profiling in the mouse chronic social stress model implicates a novel category of candidate genes integrating affective pathogenesis. Progress in Neuro-Psychopharmacology and Biological Psychiatry 105, 110086 (2021).

154 Yelo, E. et al. Dock10, a novel CZH protein selectively induced by interleukin-4 in human B lymphocytes. Molecular immunology 45, 3411-3418 (2008).

155 Lin, E.-J. D. et al. Social overcrowding as a chronic stress model that increases adiposity in mice. Psychoneuroendocrinology 51, 318-330 (2015).

156 Roltsch, E. A. et al. Predator odor stress alters corticotropin-releasing factor-1 receptor (CRF1R)-dependent behaviors in rats. Neuropharmacology 79, 83-89 (2014).

157 Fischer, C. P., Franco, L. A. \& Romero, L. M. Are novel objects perceived as stressful? The effect of novelty on heart rate. Physiology \& behavior 161, 7-14 (2016).

158 Lucca, G. et al. Effects of chronic mild stress on the oxidative parameters in the rat brain. Neurochemistry international 54, 358-362 (2009).

159 Katz, R. J. Animal model of depression: pharmacological sensitivity of a hedonic deficit. Pharmacology Biochemistry and Behavior 16, 965-968 (1982).

160 Pucilowski, O., Overstreet, D. H., Rezvani, A. H. \& Janowsky, D. S. Chronic mild stressinduced anhedonia: greater effect in a genetic rat model of depression. Physiology \& Behavior 54, 1215-1220 (1993).

161 Porsolt, R. D., Le Pichon, M. \& Jalfre, M. Depression: a new animal model sensitive to antidepressant treatments. Nature 266, 730-732 (1977).

162 Golbidi, S., Frisbee, J. C. \& Laher, I. Chronic stress impacts the cardiovascular system: animal models and clinical outcomes. American Journal of Physiology-Heart and Circulatory Physiology 308, H1476-H1498 (2015). 
163 Khasar, S. G., Dina, O. A., Green, P. G. \& Levine, J. D. Sound stress-induced long-term enhancement of mechanical hyperalgesia in rats is maintained by sympathoadrenal catecholamines. The Journal of Pain 10, 1073-1077 (2009).

164 Dunphy-Doherty, F. et al. Post-weaning social isolation of rats leads to long-term disruption of the gut microbiota-immune-brain axis. Brain, behavior, and immunity 68, 261-273 (2018).

165 Sequeira-Cordero, A., Salas-Bastos, A., Fornaguera, J. \& Brenes, J. Behavioural characterisation of chronic unpredictable stress based on ethologically relevant paradigms in rats. Scientific reports 9, 1-21 (2019).

166 Wickham, H. ggplot2: elegant graphics for data analysis. (Springer, 2016). 